\title{
Avoidance of plant foods in infancy
}

Camille Rioux ${ }^{1^{*}}$ and Annie E. Wertz ${ }^{1 *}$

Author Affiliations:

${ }^{1}$ Max Planck Institute for Human Development, Max Planck Research Group Naturalistic Social Cognition, Lentzeallee 94, 14195 Berlin, Germany.

Correspondence should be addressed to: Camille Rioux, Max Planck Institute for Human Development, Max Planck Research Group Naturalistic Social Cognition, Lentzeallee 94, 14195 Berlin, Germany. Email: rioux@ mpib-berlin.mpg.de

(C) 2021. This manuscript version is made available under the CC-BY-NC-ND 4.0 license http://creativecommons.org/licenses/by-nc-nd/4.0/

This manuscript is published in Developmental Psychology

Rioux, C., \& Wertz, A. E. (2021). Plant food avoidance in Infancy. Developmental Psychology, 57(5), 609-624. https://doi.org/10.1037/dev0001146 


\section{Abstract:}

Infants avoid touching plants. Here we examine for the first time whether infants are also reluctant to touch plant foods. We hypothesized that infants would avoid plant foods because food neophobia - the avoidance of novel foods - is particularly strong for fruits and vegetables. However, we predicted that infants would avoid processed plant foods to a lesser degree than whole leafy plants because they bear the markers of previous human engagement. In a first assessment, we presented 7- to 15-month-olds, recruited from a predominantly White population around Berlin, Germany $(\mathrm{N}=56,29$ females) with whole plants, processed plant foods, and nonplant food controls. We measured infants' latency to touch each object and their social looks toward adults prior to the first touch. In a follow-up assessment one year later, participants' caregivers filled out a questionnaire measuring their child's food neophobia. Infants avoided touching both whole plants and processed plant foods, and engaged in more social looking before touching them, relative to their matched controls. However, infants took longer to touch and engaged in more social looking for whole plants than processed plant foods. The follow-up assessment indicated that avoidance of cut plant foods in older infants was related to their food neophobia measured one year later. These results demonstrate that (i) infants avoid plant foods, (ii) cues of food processing decrease infants' reluctance to touch plant foods relative to unprocessed plants, suggesting that these cues may signal food safety, and (iii) avoiding certain types of plant foods in infancy may be a precursor of later food neophobia.

\section{Keywords: infancy; food neophobia; food processing; plant foods; social information}




\section{Introduction}

Food neophobia, or the avoidance of novel foods, is well known to occur in young children (Dovey, Staples, Gibson \& Halford, 2008; Lafraire, Rioux, Giboreau \& Picard, 2016; Rioux, 2019). Children exhibiting food neophobia do not readily accept novel foods and instead tend to show wariness and avoidance behaviors when presented with them. Food neophobia is thought to have served a protective function across evolutionary time for children by minimizing the risk of ingesting novel items, which may be harmful once children are mobile enough to reach for foods available in their environment (Pliner 1994; Rozin, 1976). Notably, plant food items such as fruits and vegetables seem to be the most commonly rejected food items in numerous studies of food neophobia (see Cole et al., 2017; Nicklaus \& Monnery-Patris, 2018 for reviews). These food items are privileged targets of food neophobia presumably because plants contain toxic secondary compounds (see e.g., Mithöfer \& Boland, 2012), some of which can be harmful if consumed by humans, and no visual features reliably signal which plants may contain these toxic compounds (Cashdan, 1994; 1998). When severe, food neophobia can have negative consequences for health by suppressing consumption of fruits and vegetables, which are a necessary component of a diet that facilitates normal and healthy development (Woodside, Young, \& McKinley, 2013). It is therefore of critical importance to investigate the cognitive underpinnings of food avoidance behaviors early in life, particularly if we are to construct effective interventions for increasing the consumption of fruits and vegetables during this critical developmental stage. In the current study we examine the developmental pathway of plant-based food reluctance behaviors in infancy.

\subsection{Precursors of food neophobia in infancy}

Food neophobia is thought to emerge only at the end of the second year of life when toddlers are mobile enough to encounter food outside parental supervision (Dovey et al., 2008). 
However, precursors of food neophobia might be present in infancy. In a series of longitudinal studies, Moding and Stifter found that infants who exhibited low approach tendencies toward new foods and high levels of food refusals at 12 months of age had high levels of food neophobia at 4 years of age. (Moding \& Stifter, 2016a; 2016b; 2018). The authors argue that food neophobia should emerge after infants transition to solid foods (and therefore novel foods), only after the first half of the first year of life. Accordingly, food related behaviors at 6 months of age (i.e., before or at the very beginning of the transition to solid food) were not predictors of later food neophobia (Moding \& Stifter, 2016a). Work from Mennella, Lukasewycz, Castor and Beauchamp (2011) seems to support this pattern of development. Infants younger that 4 months of age were more accepting of a novel bitter flavor than their 7- to 8-month-old counterparts. The developmental pattern of food neophobia also follows the development of the ability to inhibit approach tendencies and the general wariness when exposed to novelty, thought to be adaptive once infants begin locomoting (Moding \& Stifter, 2018).

To our knowledge, these are the only studies directly assessing food neophobia precursors in infancy. However, there is convergent evidence from a different line of research showing that infants exhibit behavioral avoidance of plants, which are an important component of human diets (Elsner \& Wertz, 2019; Wertz \& Wynn, 2014a; Włodarczyk, Elsner, Schmitterer \& Wertz, 2018; Włodarczyk, Rioux \& Wertz, 2020). Humans have relied on a wide variety of plant food resources over evolutionary time (e.g., Hardy \& Martens, 2016; Unger \& Sponheimer, 2011) and interactions with plants were not limited to adulthood as infants were often carried along on foraging trips (Draper \& Cashdan, 1988; Hewlett \& Lamb, 2005). Nonetheless plant foraging can be a risky task given that plants produce a variety of toxic chemicals and mechanical defenses (e.g., thorns) that can be quite harmful (Cashdan 1998; Mithöfer \& Boland, 2012; Palo \& Robbins, 1991; Włodarczyk et al., 2018). Therefore, Wertz and colleagues proposed that a behavioral avoidance strategy of minimizing physical contact 
with plants is an effective way of minimizing the risk of exposure to harmful plant toxins in infancy (e.g., Wertz \& Wynn, 2014a; Wertz, 2019). Consistent with this proposal, across a series of studies, they showed that 8- to 18-month-olds avoid touching plants compared to other types of entities, including novel artifacts that matched the plants along perceptual dimensions (i.e., green color, presence of leaf-shape parts), familiar artifacts (e.g., lamp, saucepan), and other naturally occurring entities (e.g., shells, rocks; Elsner \& Wertz, 2019; Wertz \& Wynn, 2014a; Włodarczyk et al., 2018; Włodarczyk et al., 2020). Interestingly, infants treated all plants as potentially dangerous, whether or not they possessed sharp-looking thorns, suggesting that, similar to food neophobia, this protective mechanism is initially deployed for the whole category of plants regardless of their appearance (Włodarczyk et al., 2018). The work on plant avoidance in infancy mirrors a robust finding from the food neophobia literature that young children avoid plant foods (e.g., vegetables and fruits; see Cole et al., 2017 Dovey et al., 2008; Rioux, 2019 for reviews). This suggests that plant avoidance behaviors in infancy could be related to later avoidance of plant foods and food neophobia more broadly. However, avoidance behaviors towards plant foods in infancy remain to be investigated.

\subsection{Social information influences food neophobia and reluctance to touch plants}

Food learning in humans relies heavily on social learning (see e.g., DeJesus, Kinzler \& Shutts, 2018 for a review). This is particularly true for plant foods such as fruits and vegetables because the presence of potentially harmful, if not fatal, plant toxins makes individual trial-anderror food experimentation costly and favors cognitive design for social learning (Oña, Oña, \& Wertz, 2019; Wertz, 2019; Wertz \& Moya, 2019). In fact, food neophobia decreases with social facilitation (Addessi, Galloway, Visalberghi \& Birch, 2005; Birch, 1980; Laureati, Bergamaschi \& Pagliarini, 2014). For instance, toddlers are more willing to taste a novel food if they see an adult eat it first (Addessi et al., 2005) and school-based interventions that used 
peer-modeling efficiently reduce food neophobia in young children (Laureati et al., 2014). In the case of plants, infants exhibit more social looking to adults before touching plants, a strategy that puts them in the best position to obtain information from knowledgeable individuals before touching potentially harmful plants (Elsner \& Wertz, 2019). Eighteen-month-olds also learn that a plant is edible after watching and adult eat from it, and generalize this socially learned edibility information to other similar looking plants (Wertz \& Wynn, 2014b; 2019).

The effects of social information about edibility, specifically in the form of an adult or a peer eating a food, have been well studied, including in infancy (e.g., Liberman, Woodward, Sullivan \& Kinzler, 2016). However, the effects of other forms of social information on food behaviors remain largely uninvestigated. One form of social information that has received little attention is food processing. Humans have a long history of processing food prior to consumption (e.g., chopping, cooking; Harris \& Hillman, 1989; Kaplan, Hill, Lancaster \& Hurtado, 2000; Wrangham, 2009) in ways that often reduce plant food toxicity. For example, cassava is a staple food in many African countries, yet it cannot be eaten raw because it contains toxic hydrocyanic acid that must be removed by processing techniques such as soaking in water prior to consumption (Mombo, Dumat, Shahid \& Schreck, 2016). Food processing techniques can be extremely complex, even prior to modern industrialized kitchens. For example, traditional processing techniques for acorns, a staple food item of the Chumash in present-day California, included at least five different steps and lasted up to 30 days (Timbrook, 2007). These techniques cannot be developed de novo by each individual, but are instead the result of accumulated social information transmitted from one generation to the next (e.g., Boyd \& Richerson, 2005).

Food processing can be viewed as a sign of human engagement. Both adults and young children see transformed foods (e.g., foods that have been cooked) as manmade objects that bear markers of previous human intervention (Foroni, Pergola \& Rumiati, 2013; Girgis \& 
Nguyen, 2020; Lafraire, Rioux, Hamaoui, Girgis, Nguyen \& Thibaut, 2020). These processed foods are similar to artifacts in the sense that children do not need to directly witness artifact fabrication to infer human design (Gelman, 2013; Gutheil, Bloom, Valderrama \& Freedman, 2004; Kelemen, Seston \& Saint Georges, 2012). Therefore, it is possible that cues of food processing may serve an important role in the food domain. Specifically, cues of food processing may signal food safety because they indicate that another person has already engaged with a candidate food item. At a minimum, this suggests the item is safe to handle and may also indicate that it is safe to eat. In support of this view, adults find pictures of processed foods more appealing than pictures of unprocessed foods, even when caloric content is controlled for and perceive processed foods as more ready to eat (Foroni et al.2013). Additionally, there is converging evidence that watching an adult touch a plant reduces infants' reluctance to touch plants, while the same action performed with artifacts did not affect infants' reaching behavior (Włodarczyk et al., 2020). Thus, in the current study we investigated whether cues of food processing influence infants' behavior toward plants and plant foods.

\subsection{The current experiment}

In line with the existing findings, the present research has three goals: (i) to investigate whether infants avoid touching plant foods (e.g., fruits and vegetables), (ii) to examine whether cues of food processing serve as a social signal of plant food safety, and (iii) to investigate whether infants' behaviors toward plant foods are related to later food neophobic behaviors in toddlerhood. In this study, we define a processed food as a food exhibiting signs of human intervention that alter its naturally occurring state (e.g., a picked or sliced apple instead of an apple growing on its tree; Monteiro, 2009). Highly industrially-processed foods (e.g., crackers, cakes) are included in our stimulus set, but are not the focus of the present study because infants are likely unable to track the specific industrialized transformation steps. Additionally, 
processing raw food items using non-industrialized techniques has been an important part of human life for millennia. In fact, processing techniques like picking, cutting, grinding, soaking, and cooking are still the main techniques applied to food in small-scale societies (e.g., Mombo et al., 2016).

The current experiment assessed 7- to 15-month-olds' reaching and social looking behavior towards whole plants in their naturally occurring state, processed plant foods such as picked and cut fruits and vegetables, and control objects that matched the whole plants and processed plant food objects along perceptual dimensions. We used a paradigm adapted from Wertz and Wynn (2014a), in which a series of objects were presented to infants one at a time by an experimenter seated across a table. First, we predicted that the plant avoidance strategy infants employ for whole leafy plants would extend to processed plant foods. Specifically, we predicted that infants would be more reluctant to reach for picked and cut fruits and vegetables than matched control objects. Second, given the importance of social learning in the food context, we predicted that cues of food processing would affect infants' behavior toward plant foods. Specifically, we predicted that (a) cues of food processing would reduce infants' avoidance of processed plant foods relative to whole plants, (b) infants would differentially seek out social information when confronted with processed plant foods, as they do for whole leafy plants, and (c) increasing cues of food processing would reduce infants' reluctance to touch plant foods, such that infants should reach more quickly for cut plant foods than picked plant foods.

Finally, in order to explore whether infants' behavior toward plant foods is related to later food neophobia, we contacted participants caregivers' about one year after they participated in the reaching assessment and asked them to fill out an online questionnaire that measured their child's food neophobic behaviors (Child Food Rejection Scale, CFRS; Rioux, Lafraire \& Picard, 2017; Rioux, Lafraire, Picard \& Blissett, 2019). We predicted that infants 
who were more reluctant to touch processed plant foods in the first assessment would have higher levels of food neophobia at the follow-up assessment one year later.

\section{Methods}

\subsection{Participants}

Participants were 56 healthy, full term infants, aged 7-15 months (29 female, mean age $=11$ months days; range $=7 ; 10-15 ; 22$ ) with no food allergies, recruited from a predominantly White population around Berlin, Germany. Two additional infants were tested but excluded due to fussiness during the test session. This sample size was chosen based on a power analysis using $\mathrm{G}^{*}$ Power 3.1.9.3, assuming a large effect size $\mathrm{d}=.4$ and a power of 0.8 . We assumed a large effect size for the behavioral assessment because the first study to use the present methodology reported a large effect size of object type on infants' reaching behavior (Wertz \& Wynn, 2014a) and subsequent studies using the same methodology found similar effect sizes (Elsner \& Wertz, 2019; Włodarczyk et al., 2018; 2020). This sample size also allowed us to detect medium effect size relationships between infants' behaviors toward plant foods and later food neophobia $(r=.35)$ in the longitudinal follow-up with a power of 0.8 . We assumed medium effect sizes for the longitudinal analyses because previous studies examining food behaviors in infancy and later food neophobia in toddlerhood reported medium effect sizes (Moding \& Stifter, 2016a; 2018).

Our age range was chosen to capture different types of experience with solid foods across three weaning stages for our German infants: 7 to 9 months of age, experience with pureed food; 10 to 12 months, experience with whole and cut-up food; and 13 to 15 months, experience with family food (Prell \& Koletzko, 2016) and to be similar to previous studies of plant avoidance (Elsner \& Wertz, 2019; Wertz \& Wynn, 2014a; Włodarczyk et al., 2018; 2020). The study was approved by the Ethics Committee of the Max Planck Institute for 
Human Development (study title: Tischlein Deck Dich; protocol number: i2018-04.1) and parents gave written consent for their child's participation. Parents were compensated with 10 Euros ((corresponding to approximately 12 US dollars) and infants were given a participation certificate.

\subsection{Stimuli}

Eight types of stimulus objects were presented to infants: leafy plants, plants with fruits, picked leaf bouquets, picked fruits and vegetables, cut fruits and vegetables, starchy foods, novel artifacts and naturally occurring objects (see Fig. 1), grouped into three main categories of interest: whole plants, processed plant foods and controls.

The first two types of stimuli were whole plants. The whole leafy plants allowed a direct comparison with the type of unprocessed plant stimuli used in previous studies (Elsner \& Wertz, 2019; Wertz \& Wynn, 2014a; Włodarczyk et al., 2018; 2020). The whole plants with fruits were included to investigate whether the presence of fruits changes infants' responses toward whole plants. We used realistic looking artificial plants because real plants can change over the course of data collection and previous studies have shown that infants of this age respond similarly to real plants and artificial plants (Elsner \& Wertz, 2019; Wertz \& Wynn, 2014a).

Three of our stimulus types were processed plant foods that targeted different stages of human intervention in the service of food processing. The picked leaf bouquets and picked fruits and vegetables allowed us to examine whether plant parts that someone has already removed from a plant are treated differently than whole plants growing in pots. Cut fruits and vegetables were included to investigate the effect of signs of chopping on plant foods and were cut to be larger than bite-sized. These stimuli were chosen to be similar to stimuli used in most studies of food neophobia (e.g., Cole et al., 2017) and to be unfamiliar to infants (i.e., not 
typically eaten at home; e.g., eucalyptus leaves, Thai eggplant). Their colors were similar to the colors of the fruits on the whole plant stimuli and they did not have a strong scent.

The last three types of stimuli were non-plant food controls. Starchy foods (green pasta, rice cracker) were included as a food type that is not a target of food neophobia (Cole et al., 2017) and provide a benchmark for food behaviors unlikely to be impacted by plant avoidance. They were matched for overall shape, size and color of the processed plant foods. Novel artifacts were included to control for size, shape, and color features of the whole plants. The first type of artifact matched the size and overall shape of the whole plant stimuli (see Fig. 1, Set 1). The second type of artifact matched the size and color of the whole plant stimuli (see Fig. 1, Set 2). The naturally occurring objects matched the size, color, and overall shape of the processed plant food stimuli and were included to examine whether infants were reacting to plant food entities per se, or rather using more general rules that apply to any naturally occurring (i.e., not manmade) form. Similar novel artifact and naturally occurring object stimuli were used in previous studies where infants treated both types of entities differently from whole leafy plants (Elsner \& Wertz, 2019; Wertz \& Wynn, 2014a; Włodarczyk et al., 2018). See Supplemental Material Section 1.1 for further details of the stimuli.

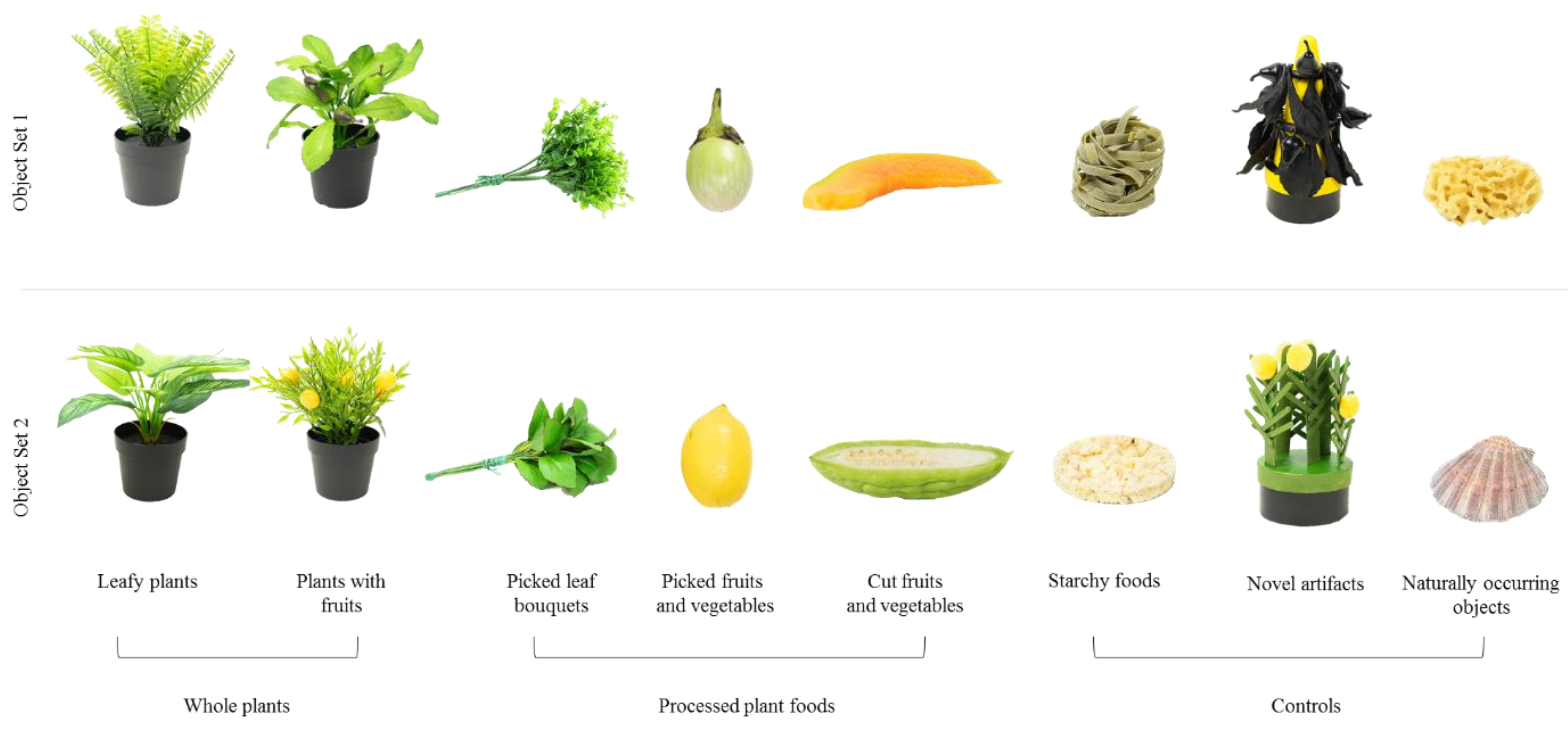


Figure 1. Stimulus objects used in the experiment. Top row: Set 1. Bottom row: Set 2. From left to right: Leafy plants, plants with fruits, picked leaf bouquets, picked fruits and vegetables, cut fruits and vegetables, starchy foods, novel artifacts, naturally occurring objects. Cut fruits and vegetables were cut to be larger than bite-sized.

The focus of our investigation was infants' behavior towards whole plants and processed plant foods, and not towards the clear plastic board on which the stimuli were presented (see Section 2.3 below) nor the pots of the whole plants or corresponding bases of the novel artifacts. The targeted areas of the stimuli were defined as areas of interest. The AOIs for the whole plant stimuli were the leaves, stems, and fruits of the plants. Correspondingly, the AOIs for the novel artifacts were the top parts of each object constructed from popsicle sticks, pompoms, and painted plastic leaves and fruits. The AOIs for the processed plant foods, starchy foods, and naturally occurring objects were the entire object, excluding the clear plastic board.

\subsection{Procedure}

Infants sat on their parents' laps, facing away the experimenter who placed the sixteen stimuli, one at a time, in front of the infant while saying in German, "Look, what I've got!" ("Schau mal, was ich hier habe!"). The objects were displayed on a clear plastic board (approximately $20 \mathrm{~cm}$ long by $10 \mathrm{~cm}$ wide); the experimenter only touched this board throughout the session to avoid cuing infants' touching behavior toward any particular part of the stimuli. The objects were displayed about $15 \mathrm{~cm}$ away from the infants and slightly on their side, enable us to code later social looking behaviors (see Video S1, in Supplementary Materials). Parents kept their eyes closed throughout the session and the experimenter looked down at the table and maintained a neutral expression while each object was in front of the infant. The sixteen stimuli were grouped into two sets of eight objects according to overall 
shape and color (see Fig. 1). The two sets were presented to each infant with a small break between the presentations; Within each set, the objects were presented in a counterbalanced order so that each object was presented an equal number of times across participants in each position within a set (e.g., first position, second position, eighth position, etc.). The presentation order of the two sets was counterbalanced across participants.

Trials terminated (i) when the infant touched the AOI of the stimulus object, or (ii) 30 seconds elapsed without a touch to any part of the object or with touches only to non-AOI parts of the object (e.g., the clear plastic board). Thirteen trials (out of a total of 896) were excluded from analysis due to infants throwing a stimulus object on the ground ( 5 trials), having another object in hand during the trial (1), and procedure error (7). As in previous studies (Elsner \& Wertz, 2019; Włodarczyk et al., 2018, 2020), we excluded trials within an infants' session if a stimulus object was thrown on the ground, or when infants had another object in their hands, because it disturbed the flow of the trial. Only a small proportion of trials were excluded due to this reason.

\subsection{Coding infants' behavior}

\subsubsection{Coding infants' touch behavior}

Infants' touch behavior towards to the AOI of the stimulus object was coded during each trial (see SM Section 1.2. for a description of the video set up). For the whole plants with fruits and novel artifacts, we also coded separately touches to the leaf parts and to the fruit parts. Each trial began when the side of the plastic board closest to the infant made contact with the table as the experimenter placed the object in front of the infant, and ended as outlined in Section 2.3. A touch was coded as any part of the infant's hand coming into contact with the stimulus object. From this coding we extracted touch latencies (continuous variable). The touch latency for each object was the elapsed time before infants' first touch to an object's AOI; if 
infants did not touch the object during the trial, this was coded as the maximum trial length of 30s. For the whole plants with fruits and novel artifact stimuli, we also extracted the number of touches towards the leaf and fruit parts (count variable) and latencies to touch the leaf and fruit parts (continuous variable; see SM Sections 2.1.3. and 2.1.4. for an analysis of these leaf and fruit touch variables).

\subsubsection{Coding infants' looking behavior}

Infants' looking behavior towards the objects, their parents, and the experimenter were coded during each trial. The majority of infants' looks were toward the experimenter seated directly across the table while fewer looks were directed back at the parent. Each trial began when the object was visible to the infant as it was brought from behind the curtain on our presentation stage and ended as outlined in Section 2.3. From this coding we extracted infants' social looking frequency (count variable) and duration (continuous variable). Following Elsner \& Wertz (2019), social looks were defined as looks towards the experimenter or the parent that were immediately preceded by a look toward the stimulus object (maximum delay: $500 \mathrm{~ms}$ ). This behavior was defined as "social looking" and not "social referencing" because social referencing is a two-stage process that involves first looking to an adult in response to an ambiguous stimulus or a situation of epistemic uncertainty (Bazhydai, Wertmann \& Paris, 2020; Dunn \& Bremner, 2016; Hembacher, de Mayo \& Frank, 2017) and then adjusting behavior based on observing an adult's reaction (e.g., Feinman, 1982; Schimtow \& Stenberg, 2013). In our task, the adult does not react to the stimuli and, accordingly, we do not assess any subsequent modulation of infants' behavior. Therefore, we have adopted the more precise term "social looking" to refer to the first step of social referencing. 


\subsubsection{Reliability coding}

A randomly selected $25 \%$ of the videos were coded by a second independent coder. Coder agreement was high for all primary dependent variables: latency (Pearson's correlation $r=.99)$, social looking frequency $(\kappa=0.75)$ and social looking duration (Pearson's correlation $r=.96)$. The experimenter's behavior was also coded by two independent coders in order to assess whether the experimenter's behavior during the object presentation phase may have inadvertently influenced infants' responses toward our different stimulus types. The coding indicated that the experimenter did not exhibit systematically different behaviors across trials (see SM Section 1.3. for further details of this analysis).

\subsection{Parent questionnaires}

In order to investigate the potential role of infants' prior experiences and temperament, parents completed a battery of four questionnaires. The first questionnaire, the Plant Experience Questionnaire (Elsner \& Wertz, 2019; Wertz \& Wynn, 2014a; Włodarczyk et al., 2018; 2020) assessed infants' experience with indoor and outdoor plants during the last months and during the last summer months.

Parents filled out a second questionnaire about their infant's experience with the particular study objects: Thai eggplant, lemon, papaya, bitter cucumber, green pasta, rice cracker, natural sponge, and seashell. The first two questionnaires were filled out during the break between the two experimental sessions and the order was counterbalanced across participants.

After the experimental sessions concluded, parents filled out two more questionnaires; the order was also counterbalanced across participants. The third questionnaire consisted of three subscales of the Revised Infant Behavior Questionnaire (Garstein \& Rothbart, 2003): fear, perceptual sensitivity and approach. Each of these subscales assesses aspects of infants' 
behavior that could potentially affect the way they manually explore objects and contribute to neophobia.

The fourth questionnaire was a Food Frequency Questionnaire (Mensink \& Burger, 2004) that assessed infants' food habits and consumption to examine whether they are associated with infants' reaching behavior toward the stimulus objects, particularly the food stimuli. This questionnaire also asked at which month the following foods were introduced into their infant's diet: jarred foods, pureed fruits and vegetables with milk, pureed fruits and vegetables without milk, whole fruits and vegetables, and family food. (See SM Section 1.4. for further details of the questionnaires).

\subsection{Follow-up assessment of food neophobia}

Finally, in order to examine whether behaviors toward plant foods in infancy are related to food neophobia in toddlerhood, participants' caregivers were contacted one year after the first assessment to fill out an online questionnaire about their child's food neophobic behaviors (Child Food Rejection Scale, CFRS; Rioux et al., 2017; Rioux et al., 2019). The youngest infants in the present study were 7 months old during the first behavioral assessment, therefore all infants were at least in the second half of their second year of life during the followup food neophobia assessment (Mean age $=23$ months,; range: 19-27). It is precisely during this period that food neophobia is thought to emerge (Dovey et al., 2008). Caregivers were asked to what extent they agree with eleven statements regarding their child's food neophobia (e.g., "My child is constantly looking for familiar foods") and pickiness ("My child refuses certain foods due to their texture") on a five-point Likert scale $(1=$ strongly disagree to $5=$ strongly agree) and a food rejection score was computed for each child (ranging from 11 to 55, with higher scores indicating higher levels of food rejection behaviors. 


\section{Results}

In order to test whether infants exhibit behavioral avoidance of whole plants and processed plant foods, and to examine their sensitivity to cues of food processing, we assessed infants' reaching behavior toward each stimulus object. We also assessed infants' social looking behavior before touching the stimuli to examine whether infants seek social information prior to touching processed plant foods like they do for whole leafy plants. Finally, we assessed the relationship between infants' reaching behavior and their food neophobic behaviors about one year later. All analyses were performed in the R environment using a generalized linear mixedeffects approach (Bates, Mächler, Bolker, \& Walker, 2014). In all models, infant participants served as a random factor to account for shared variances within subjects, whereas Object Type (whole plants, processed plant foods, starchy foods, novel artifacts, and naturally occurring objects), Order of presentation (continuous factor) and Age (continuous factor) were modeled as fixed effects. We first investigated Object Type differences between our five broad categories of interest. We then investigated differences within the whole plants and processed plant food categories, as objects within each of these categories had different characteristics that could influence latency (e.g., the presence or absence of fruits on plants). We always singled out the control objects in the analysis as previous studies found that infants react differently towards these objects (Elsner \& Wertz, 2019; Wertz \& Wynn, 2014a, Włodarczyk et al., 2020). Object Type was our main variable of interest and Age was considered as a covariate that could potentially modulate the effect of Object Type. We treated age as a continuous variable because we were not sure whether different categories of experience with solid foods would influence infants' behavior toward our stimuli, and because of the limited sample size within each age range. Finally, Order of presentation was included as a control variable (i.e., only its main effect was tested). To estimate the effect of the specific object types on infants' behavior, we calculated contrasts between the different object types using the multicomp package function 
glth (Bretz, Hothorn \& Westfall, 2010). We report the ANOVA output results for the models throughout. The values in the text and on the graphs report the optimal model values and all reported tests use Bonferroni-corrected alpha levels to account for multiple comparisons. The means and standard deviations in the tables report the raw data for comparability across different analyses.

\subsection{Infants' latency to touch the different stimuli}

In order to test our hypothesis that infants would avoid touching whole plants and processed plant foods, we first analyzed whether infants were less likely to touch whole plants and processed plant foods than control objects by looking at whether they ever touched the different stimuli (Yes/No). We found that, consistent with previous findings, infants were less likely to touch whole plants compared to all objects. However, infants were not less likely to touch processed plant foods compared to their starchy food and naturally occurring object controls (see SM Section 2.1.1. for this binary analysis). Next, we moved to our main analysis assessing the time elapsed before infants touched the different types of stimulus objects (Latency). Trials without a touch were excluded from this analysis to avoid a bimodal distribution, which is poorly modeled with standard distributions (138 trials out of 883; see SM Section 2.1.2. for an analysis with these trials included). Latency values were analyzed with a generalized linear mixed effects model (GLMM) using a Gamma distribution to model the response time data (Lo \& Andrews, 2015; Santhanagopalan, Chetty, Foale, Aryal \& Klein, 2018). The results revealed a significant effect of Order of object presentation $(\chi 2(1)=18.07$, $\mathrm{p}<.0001$, marginal pseudo $R^{2}=.01$ ), indicating that the time infants took to touch an object decreased as the session progressed. Importantly, the results also revealed a significant effect of Object Type $\left(\chi 2(7)=81.95, \mathrm{p}<.0001\right.$, marginal pseudo $R^{2}=.07$, see Fig. 2$)$. There was no main effect of Age nor an Age x Object Type interaction. 
Running head: Avoidance of plant foods in infancy

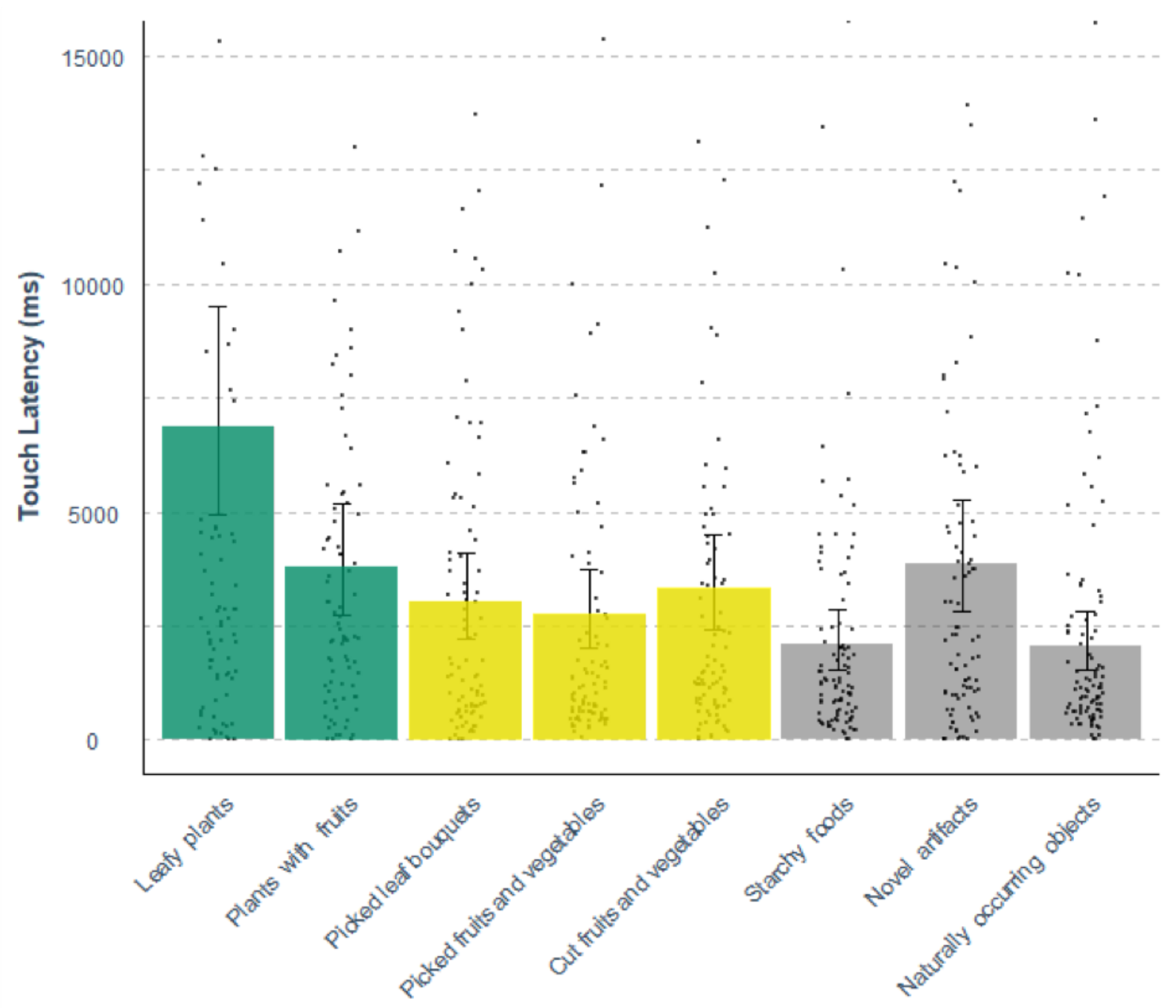

Figure 2. Infants' latency to touch the different stimuli. Green bars: Whole plants; Yellow bars: Processed plant foods; Grey bars: Non-plant food controls. Data points represent individual trials. Error bars depict standard errors. Duration values below $15000 \mathrm{~ms}$ for individual trials are reported on the figure. Duration values above $15000 \mathrm{~ms}$ for individual trials are not shown on the figure, resulting in the following number of trials not shown for each stimulus object: Leafy plants (13); Plants with fruits (5); Picked leaf bouquets (5); Picked fruits and vegetables (9); Cut fruits and vegetables (7); Starchy foods (6); Novel artifacts (9); Naturally occurring objects (9). 
Table 1 summarizes the significant differences yielded by the main effect of Object Type on infants' reaching behaviors (see also SM Table S1 for descriptives). Consistent with previous findings (Elsner \& Wertz, 2019; Wertz \& Wynn, 2014a; Włodarczyk et al., 2018; 2020), infants' latency to touch whole plants was longer than their latency to touch any of the other stimulus types. Additionally, in contrast to the binary touch analysis described above (see also SM Section 2.1.1.) and as predicted by a behavioral avoidance of plant foods, infants' latency to touch processed plant foods was longer than their latencies to touch starchy foods and naturally occurring objects, but shorter than their latency to touch novel artifacts.

There were interesting differences in infants' latency to touch the objects within the whole plant category. Infants' latency to touch leafy plants was longer than their latency to touch plants with. None of the comparisons within the processed plant food category were significant, suggesting that infants responded similarly to picked and cut fruits and leaves. Within the non-plant food control object category, infants' latency to touch novel artifacts was longer than their latency to touch starchy foods and naturally occurring objects.

The latency results provide support for our hypothesis that infants would avoid touching processed plant foods, but to a lesser degree than whole unprocessed plants. However, this difference was limited to leafy plants. 
Table 1: Summary of significant differences from the main effect of Object Type on infants' reaching behaviors.

\begin{tabular}{|c|c|c|c|}
\hline \multicolumn{2}{|c|}{ Object Types } & \multirow{2}{*}{$\begin{array}{l}\text { Mean Differences (ms) } \\
1237.89\end{array}$} & \multirow{2}{*}{$\begin{array}{l}\text { Estimates and Significance } \\
b=1.57, S E=.31, z=5.09 * * *\end{array}$} \\
\hline Whole plants & Processed plant foods & & \\
\hline & Novel artifacts & 201.00 & $b=1.12, S E=.53, z=2.07 *$ \\
\hline & Naturally occurring objects & 2500.07 & $b=3.60, S E=.53, z=6.82 * * *$ \\
\hline & Starchy foods & 2125.84 & $b=1.76, S E=.26, z=6.71 * * *$ \\
\hline \multirow[t]{3}{*}{ Processed plant foods } & Novel artifacts & -1036.90 & $b=-.74, S E=.36, z=2.05^{*}$ \\
\hline & Naturally occurring objects & 1262.19 & $b=1.12, S E=.36, z=3.13 * *$ \\
\hline & Starchy foods & 887.96 & $b=1.07, S E=.36, z=3.00 * *$ \\
\hline \multirow[t]{2}{*}{ Novel artifacts } & Naturally occurring objects & 2299.08 & $b=.016, S E=.14, z=4.28 * * *$ \\
\hline & Starchy foods & 1924.85 & $b=.60, S E=.14, z=4.13^{* * *}$ \\
\hline Leafy plants & Plants with fruits & 2012.87 & $b=.59, S E=.161, z=3.71^{* * *}$ \\
\hline
\end{tabular}

Note. $\mathrm{P}$ values $<.001$ are marked with $* * *, \mathrm{p}$ values $<.01$ with $* *$ and $\mathrm{p}$ values $<.05$ with*. Differences within one of the five broad categories are marked in italics. $b=$ model estimates, $S E=$ standard errors, $z=\mathrm{z}$ values.

\subsection{Infants' looking behavior}

Second, to investigate whether infants engaged in more social looking before touching whole plants and processed plant foods, we analyzed the proportion of infants' social looking in the pre-touch phase relative to their touch latency using a generalized linear model with Gamma distribution. This analysis accounted for the differing amounts of time before infants touched the different object types by calculating the proportion of time infants spent social looking before touching each stimulus object (see SM Sections 2.2.1 and 2.2.2 for analyses of the frequency of social looks and the absolute time spent social looking; in both analyses an effect of Object Type was found). The results revealed a significant effect of Order of object presentation $\left(\chi 2(1)=40.29, \mathrm{p}<.0001\right.$, marginal pseudo $\left.R^{2}=.03\right)$. The proportional time infants spent social looking before touching an object decreased as the session unfolded. 
Importantly, as predicted, this analysis also showed a significant effect of Object Type $\left(\chi^{2}(7)=\right.$ 78.34, $p<.001$, marginal pseudo $R^{2}=.05$, see Fig. 3). As with infants' reaching behavior, there was no main effect of Age nor an Age x Object Type interaction.

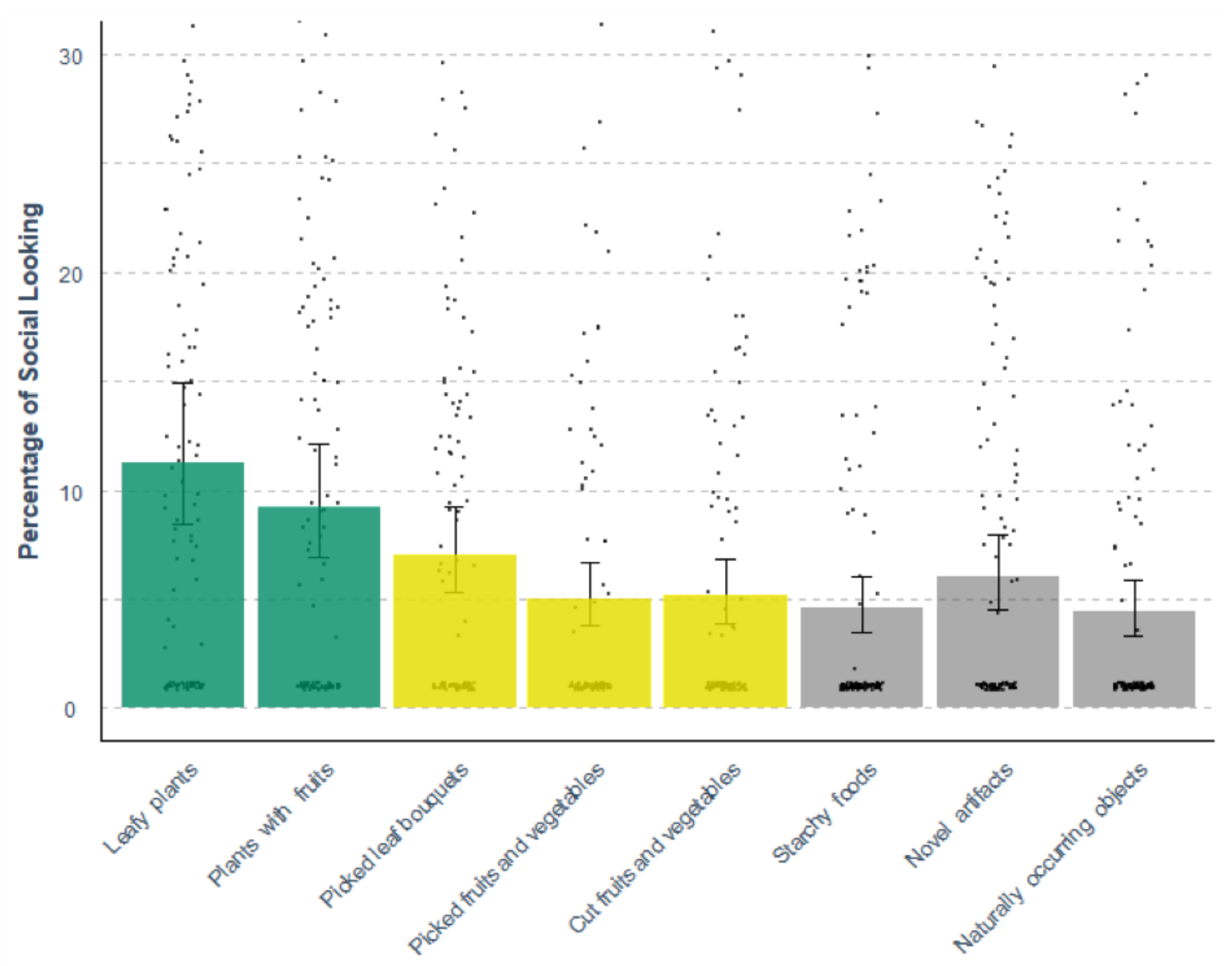

Figure 3. Infants' looking behavior. Green bars: Whole plants; Yellow bars: Processed plant foods; Grey bars: Non-plant food controls. Data points represent individual trials. Error bars depict standard errors. Percentage values below $30 \%$ for individual trials are reported on the figure. Percentage values above $30 \%$ for individual trials are not shown on the figure, resulting in the following number of trials not shown for each stimulus object: Leafy plants (7); Plants with fruits (10); Picked leaf bouquets (4); Picked fruits and vegetables (11); Cut fruits and vegetables (4); Starchy foods (1); Novel artifacts (4); Naturally occurring objects (2). 
Table 2 summarizes the significant differences yielded by the main effect of Object Type on infants' social looking behaviors (see also SM Table S2 for descriptives). The proportional amount of social looking was significantly higher for whole plants compared to processed plant foods and controls, replicating the pattern observed in Elsner \& Wertz (2019). Consistent with the importance of social cues for food learning, infants proportional social looking was also significantly higher for processed plant foods compared to naturally occurring objects and marginally higher compared to starchy foods, but did not differ from novel artifacts $(\mathrm{p}>.05)$

In contrast to the touch latency results, within the whole plant category, infants did not differ in their relative amount of social looking for leafy plants and plants with fruits $(\mathrm{p}>.05)$. However, within the processed plant food category, infants' social looking was significantly higher for picked leaf bouquets compared to picked and cut fruits. Within the control object category, social looking was significantly higher for novel artifacts compared to naturally occurring objects and marginally higher than for starchy foods.

These results indicate that, similar to the latency results, infants look more to adults prior to touching processed plant foods, although they engage in even more social looking for whole unprocessed plants. In this case, infants treated whole leafy and plants with fruits similarly, and the social looking effect for the processed plant foods seems to be driven by the picked leaf bouquets. 
Table 2: Summary of significant differences from the main effect of Object Type on infants' social looking behaviors.

\begin{tabular}{|c|c|c|c|}
\hline \multicolumn{2}{|c|}{ Object Types } & \multirow{2}{*}{$\begin{array}{l}\text { Mean Differences (ms) } \\
4.86\end{array}$} & \multirow{2}{*}{$\begin{array}{l}\text { Estimates and Significance } \\
b=1.75, S E=.27, z=6.37^{* * *}\end{array}$} \\
\hline Whole plants & Processed plant foods & & \\
\hline & Novel artifacts & 3.19 & $b=2.08, S E=.49, z=4.23^{* * *}$ \\
\hline & Naturally occurring objects & 6.09 & $b=3.32, S E=.50, z=6.65^{* * *}$ \\
\hline & Starchy foods & 6.15 & $b=1.59, S E=.25, z=6.42 * * *$ \\
\hline \multirow[t]{2}{*}{ Processed plant foods } & Naturally occurring objects & 1.23 & $b=.73, S E=.35, z=2.09^{*}$ \\
\hline & Starchy foods & 1.29 & $(b=.63, S E=.35, z=1.80$ \\
\hline \multirow[t]{2}{*}{ Novel artifacts } & Naturally occurring objects & 2.90 & $b=1.24, S E=.57, z=2.17^{*}$ \\
\hline & Starchy foods & 2.96 & $b=.82, S E=.43, z=1.92$ \\
\hline Picked leaf bouquets & $\begin{array}{l}\text { Picked fruits } \\
\text { Cut fruits }\end{array}$ & $\begin{array}{l}0.83 \\
2.19\end{array}$ & $\begin{aligned} b & =.33, S E=.14, z=2.32^{*} \\
b & =.30, S E=.14, z=2.12^{*}\end{aligned}$ \\
\hline
\end{tabular}

Note. $\mathrm{P}$ values $<.001$ are marked with ${ }^{* * *}, \mathrm{p}$ values $<.01$ with ${ }^{* *}, \mathrm{p}$ values $<.05$ with* and $\mathrm{p}$ values $<.1$ with.

Differences within one of the five broad categories are marked in italics. $b=$ model estimates, $S E=$ standard errors, $z=\mathrm{z}$ values

\subsection{Parent Questionnaires}

In order to investigate the role of infants' prior experiences and temperament, parents completed a battery of four questionnaires in a counterbalanced order. Analyses revealed that most of the questionnaire measures were not systematically related to touch latency, or proportional social looking (see SM Section 2.4. for further details). Of particular interest was that none of the questions assessing infants' prior experiences with plants were related to infants' reaching behavior, partially replicating previous findings in which most of the plant questionnaire measures were also not systematically related to touch latency (Elsner \& Wertz, 2019; Wertz \& Wynn, 2014a; Włodarczyk et al., 2018; 2020).

Infants' prior experience with the particular stimuli used in our study and with foods in general as measured by the Food Frequency Questionnaire (Mensink \& Burger, 2004) were not 
related to their touch latency or their social looking. It is important to note that we chose stimuli to be a priori unfamiliar to infants and parents' responses to these questionnaires confirmed that it was indeed the case. For all stimuli except the rice cracker, familiarity ratings were below 2.1 (ratings could range from 1 to 5, with 1 indicating that infants have never interacted with the object before, see SM, Section 2.4. and Table S8). It is also worth noting that, even if exposure to food items such as fruits and vegetables increased with age, exposure to the specific food stimuli used in the present study (e.g., Thai eggplant) was not correlated with age (all $r^{\prime} s<.15$ and $\left.p^{\prime} s>.2\right)$.

Finally, no significant correlations were found between touch latency towards our five categories of interest and infants' temperament.

\subsection{Follow-up assessment of food neophobia}

We contacted 52 participants' caregivers approximately one year after the behavioral assessment (for the remaining four, the contact information was no longer valid) and all agreed to participate in the follow-up. Of this sample, $\mathrm{N}=47$ completed the online CFRS questionnaire using a link sent via email to assess their child's food neophobic behaviors ( 27 females, mean age $=23$ months; range $=19-27)$. After this attrition, we could still detect medium effect sizes $(r=0.35)$ as reported by Moding \& Stifter $(2016 \mathrm{a} ; 2018)$ with a power of $80 \%$. The children's scores on the CFRS ranged from 16 to $42(\mathrm{M}=31.2, \mathrm{SD}=6.17)$, with a higher score indicating more food rejection behaviors; the distribution was similar to previous studies using the CFRS (Rioux et al., 2017; 2018; 2019).

To examine whether infants' reluctance to touch plant foods may be predictive of later food neophobia, we conducted a planned correlational analyses between latency measures and CFRS scores on the entire sample. We used Spearman correlations to account for the nonnormality of the data. In this planned analysis, we first investigated whether CFRS scores were 
correlated with infants' latencies to touch our five broad categories of interest (i.e., whole plants, processed plant foods, starchy foods, novel artifacts, and naturally occurring objects). We next investigated whether CFRS scores were correlated with infants' latencies to touch the three different processed plant foods (i.e., picked leaf bouquets, picked fruits, and cut fruits) because fruits and vegetables are well known targets of food neophobia (e.g., Cole et al., 2017). If a correlation was found between infants' latencies to touch a type of processed plant food and CFRS scores, we also tested whether the correlation coefficient was significantly different from the one between infants' latencies to touch starchy foods and CFRS scores; these two food categories (plant vs. starchy foods) are often contrasted in the neophobia literature (e.g., Cole et al., 2017; Nicklaus \& Monnery-Patris 2018).

Our planned correlational analysis on the whole sample revealed no significant correlations between our five categories of interest (or within the processed food category) and later neophobia.

We then conducted a second exploratory analysis in which we separated our infant sample into two age groups based on studies showing that lower levels of food acceptance in older infants (12-month-olds), but not younger infants (6-month-olds), predict increased food withdrawal behaviors and neophobia at 1.5 and 4.5 years of age (Moding \& Stifter, 2016a; 2018). Therefore, we chose to split our sample to separate out our youngest participants who were in the age group representing the early stages of their weaning in Germany (see Section 2.1 above): infants younger than 10 months at the first assessment $(\mathrm{N}=15)$ and infants 10 months and older $(\mathrm{N}=32)$. We conducted correlational analyses within each age group. At the time of the follow-up assessment, the two age groups did not differ in their CFRS scores $\left(\mathrm{M}_{7 \text {-to 9-month-old }}=29.53, \mathrm{M}_{10 \text {-to 15-month-old }}=31.97, p=.17\right)$.

The exploratory correlational analysis revealed no significant correlations between our five categories of interest and later neophobia in either younger or older infants. We observed 
only a trend in the older age group between the time spent looking at processed plant foods during the first assessment and later neophobia (Spearman's $r=.37, p=.059$ ). In contrast, the correlation between infants' time spent looking at starchy food items and CFRS scores was close to zero (Spearman's $r=.03, p=.83$ ). The difference between these two correlation coefficients was significant $(\mathrm{t}=2.67, p=.0098)$.

Notably, the exploratory correlational analysis of the items within the processed plant food category revealed that latency to touch cut plant foods was significantly correlated with later food neophobia in the older age group $(r=.37, p=.042$, see Figure 4). Infants who had displayed a higher reluctance to touch cut fruits and vegetables at 10-15 months of age were more likely to have higher food neophobic dispositions later in toddlerhood. The same correlation was not significant in the younger infants $(r=.02, p=.9)$. In contrast, the correlation between the older infants' latency to touch starchy food items (i.e., items that are not targets of food neophobia; Cole et al., 2017) and later food neophobia was close to zero $(r=.07, p=.92$, see Figure 4). The difference between these two correlation coefficients was significant ( $\mathrm{t}$ $=2.12, p=.037)$. These findings indicate that toddlers' food neophobic dispositions tended to be better predicted by their earlier behaviors towards cut fruits and vegetables than their behaviors towards starchy foods.

Interestingly, infants' behaviors toward whole plants and picked fruits and vegetables were also not related to later food neophobia (see Table S11 for the full correlation table), indicating that older infants' behavior toward cut plant foods seems to be particularly important for later food neophobia. Critically, this finding does not depend on one particular age split. We chose the age spilt above to correspond to the weaning categories represented in our sample (see Section 2.1 above), but we observe similar results if we split our sample differently (e.g., splitting the sample at 12 months of age following the Moding \& Stifter (2016a; 2018) finding, or splitting our sample exactly in half; see SM Tables S11 and S12 for further details). This 
suggests that certain plant food behaviors play an important role in the development of food neophobia, starting in the latter half of the first year of life.
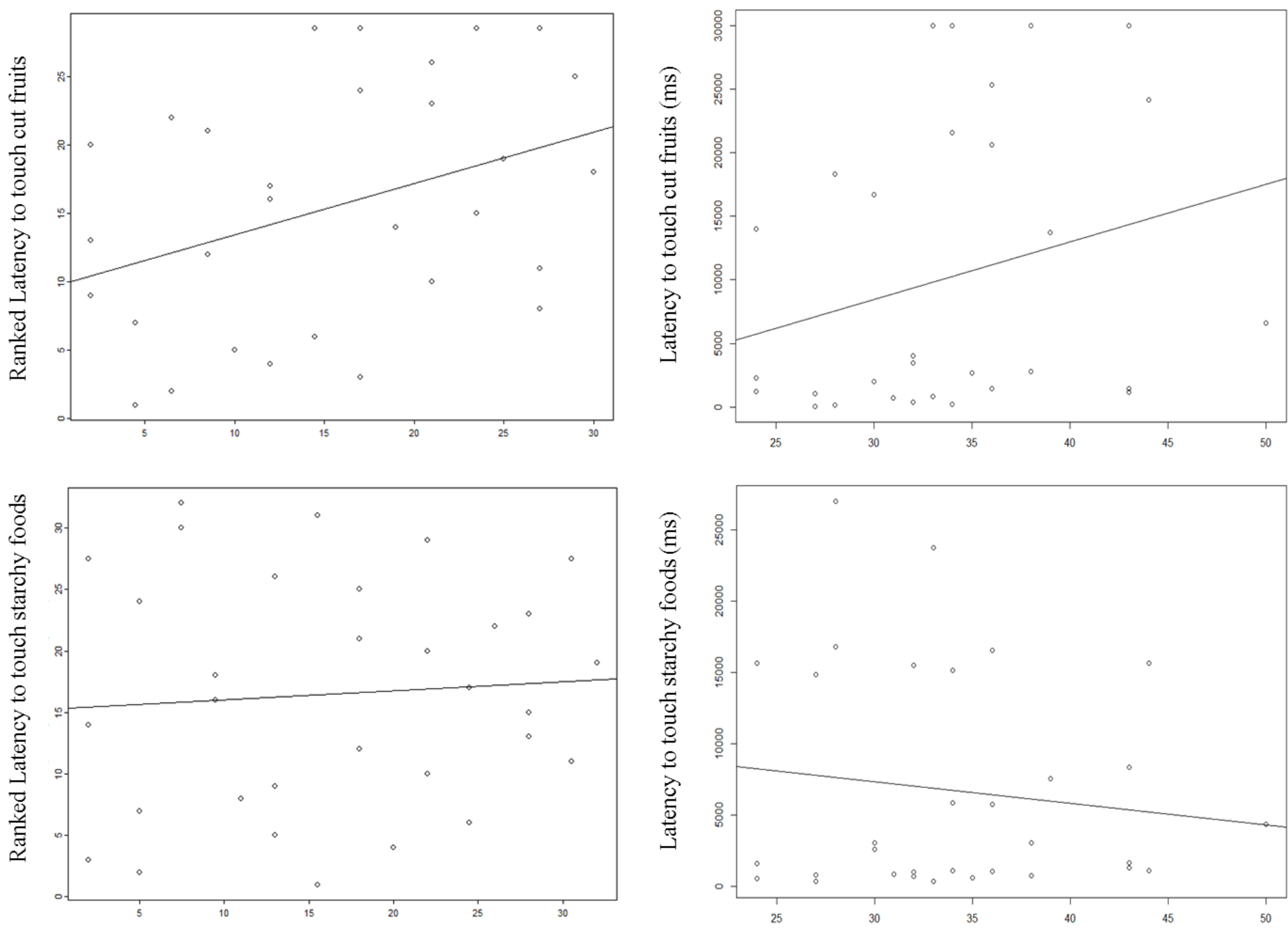

Ranked Food Rejection Scores

Food Rejection Scores

Figure 4. Infants' latencies to touch cut fruits (top row) and starchy foods (bottom row) as a function of neophobic behaviors approximately one year later. The left panels depict the ranked latency and food rejection values with regression lines representing Spearman correlation coefficients. In order to account for the non-normality of the data, our analyses 
were conducted using the ranked scores. The right panels depict the raw latencies and food rejection scores with regression lines depicting Pearson's correlations. The raw values are included here for transparency.

\section{Discussion}

The aims of this study were (i) to investigate whether infants avoid touching plant foods (e.g., fruits and vegetables), (ii) to examine whether cues of food processing serve as a social signal of plant food safety, and (iii) to investigate whether infants' behaviors toward plant foods are related to later food neophobic behaviors in toddlerhood. Our results show that 7- to 15month-old infants were more reluctant to touch processed plant foods than feature-matched controls, while remaining most avoidant of whole leafy plants. Infants looked toward adults most often before touching unprocessed whole plants, but also engaged in increased social looking for processed plant foods, particularly the picked leaf bouquets. These findings provide new insights into plant avoidance behaviors in infancy and suggest that cues of food processing (i.e., plant parts that have been picked and cut) serve as a social signal that plant foods are safer to touch, although not as safe as starchy foods. Additionally, the results of the longitudinal follow-up indicate that older infants' reluctance behaviors toward cut plant foods may be related to food avoidance behaviors one year later. Although the exploratory longitudinal findings require further testing, they provide an important connection to the food neophobia literature.

\subsection{Avoidance of plant foods in infancy}

The current results demonstrate that infants were more reluctant to touch whole plants and processed plant foods compared to their respective matched controls. This pattern supports our prediction, replicates previous findings that infants avoid whole leafy plants (Elsner \& 
Wertz, 2019; Wertz \& Wynn, 2014a; Włodarczyk et al., 2018; 2020), and adds two novel dimensions to our understanding of plant avoidance in infancy. First, our study demonstrates that infants show behavioral avoidance of plant foods, which are well-known targets of food neophobia in toddlerhood (e.g., Cole et al., 2017), albeit to a lesser degree than leafy plants. Second, there was an unanticipated finding that infants were less avoidant of whole plants with fruits than whole leafy plants. We will discuss these two points in turn.

Infants' avoidance of plant foods, like their avoidance of whole leafy plants, is thought to stem from the presence of potentially harmful toxins in plants (e.g., Cashdan, 1994; 1998; Wertz, 2019; Wertz \& Wynn, 2014a). Our findings are consistent with this interpretation and speak against several alternative hypotheses. Infants' latencies to touch whole plants and processed plant foods were not related to age or infants' previous experience with plants or foods in general (as measured by the Plant Experience Questionnaire [Wertz \& Wynn, 2014a] and the Food Frequency Questionnaire [Mensink \& Burger, 2004]), replicating previous findings (Elsner \& Wertz, 2019; Wertz \& Wynn, 2014a; Włodarczyk et al., 2018; 2020). The lack of age and general experiential effects may seem surprising, particularly given our broad age range. However, both the behavioral avoidance strategy for plants and food neophobia are targeted toward the avoidance of novel items. It is therefore reasonable that, for example, older infants who are already familiar with several vegetables (e.g., carrots and zucchinis) would nevertheless display neophobic behaviors toward a novel vegetable (e.g., a Thai eggplant) because they do not have information about whether this new vegetable is harmful or safe to eat. Indeed, our parent questionnaires confirmed that the particular food items used in the present study were unfamiliar to infants, irrespective of their age.

One finding that may seem at odds with our claim that infants are avoidant of processed plant foods is that infants took longer to touch novel artifacts than processed plant foods. An alternative explanation for our finding then might be an avoidance of novelty in general, which 
develops at around 7 months (Moding \& Stifter, 2018; Putnam \& Stifter, 2002). Our novel artifacts were by design completely novel to the infants, yet neither infants' latency to touch the novel artifacts or any of our other stimuli were related to their general wariness toward novel objects (as measured by the fear and approach subscales of the IBQ-R). A novelty alternative explanation predicts that the novel artifacts should be the most avoided objects in our stimulus set. However, in the current study, as well as all previous studies using this methodology (Elsner \& Wertz, 2019; Wertz \& Wynn, 2014; Włodarczyk et al., 2018; 2020), infants were faster to touch the novel artifacts than the whole leafy plants, which would be more familiar to infants as a general category. Additionally, in some previous studies that used both novel and familiar artifacts (e.g., books, lamps, brush), there were no differences in infants' latencies to touch the novel and familiar artifacts (Włodarczyk et al., 2018; Elsner \& Wertz, 2019). In fact, in Włodarczyk et al. (2020), infants' latencies to touch novel artifacts were actually shorter than their latencies to touch familiar artifacts. We believe that these findings speak against a mere novelty account of the current findings.

It remains an open question exactly why infants' touch latencies for the novel artifacts tend to be longer than other control items. It could be because they shared some perceptual features with whole plants (as they were designed to do) and were therefore avoided to a greater degree (although not as much as leafy plants), or because they tend to be larger than the other control stimuli (size does seem to play some role in past datasets, but does not account for the differences from plants; e.g., Wertz \& Wynn, 2014a), or it could be because they are novel (in some cases, infants reach more quickly for familiar objects; Shinskey \& Munakata, 2005). To be clear, the current results cannot be attributed to size differences alone. In the current study, infants were more reluctant to touch processed plant foods than their size-matched starchy food and natural object controls. Similarly, infants were more reluctant to touch leafy plants than plants with fruits that were of the same size. 
Although a novelty alternative hypothesis cannot account for our data, we are not claiming that novelty plays no role in infants' responses to different kinds of entities. In fact, the definition of food neophobia is the avoidance of novel foods, and infants may indeed be more avoidant of novel plant foods than familiar ones. However, this is something we cannot examine with our current data because we chose all of our plant food stimuli to be unfamiliar to infants (the same is true of our starchy food and natural kind controls) and the results of our familiarity questionnaire confirmed our assumptions. Future studies that include both familiar and unfamiliar foods can directly assess the role of novelty in infants' responses to plant foods.

Another alternative explanation suggested by a helpful reviewer is that infants may be simply avoiding leafy things in our stimulus set and not avoiding plant foods per se. If true, this explanation could account for the longer latencies for novel artifacts (which have some leafy features) and increased social looking for the picked leaf bouquets. This alternative explanation predicts that the leafy things in our stimulus set should all be avoided to (roughly) the same degree, and that leafy things should be avoided more than the non-leafy stimuli. However, contrary to this alternative proposal, we find some significant differences between leafy things: Infants exhibited significantly longer touch latencies for whole plants than novel artifacts and are more reluctant to touch leafy plants than plants with fruits, picked leaf bouquets, and novel artifacts. Further, infants do not avoid all leafy things more than non-leafy things. For example, there are no differences between infants' touch latencies for leaf bouquets, picked fruits, and cut fruits. Thus, infants are not just avoiding leafy things.

The second novel, and in this case unexpected, finding is that infants exhibited less reluctance to touch whole plants with fruits than whole leafy plants. Both of these plant types were completely unprocessed and previous findings indicated that the presence or absence of different plant parts (e.g., thorns) did not significantly impact infants' reaching behavior (Włodarczyk et al., 2018; 2020). Additionally, both the leaves and fruits of plants contain toxic 
secondary compounds (Cipiollini \& Levey, 1997a; 1997b), meaning that it is not necessarily a safe strategy to touch fruits instead of leaves. Why then might infants have approached plants with fruits more rapidly? It is possible that infants found the plants with fruits interesting because they were attracted to these more visually complex objects. In favor of this hypothesis, our supplementary analysis of infants' behavior toward the feature-matched novel artifacts showed that infants touched the protuberant pompoms and black "fruit" parts of the novel artifacts more quickly and more often than the "leafy" parts of the novel artifacts. However, although infants reached for plants with fruits faster than leafy plants in the main analyses presented above, our supplementary analyses showed that they still exhibited caution toward plant fruits. Infants touched the "fruit" parts of novel artifacts more frequently than the fruits on the plants, and they touched plant fruits and plant leaves with the same frequency. Additionally, infants' social looking behaviors for leafy plants and plants with fruits did not differ, showing that not all aspects of infants' behavior diverged for leafy plants and plants with fruits. Future studies could investigate whether our observed pattern of response is specific to presence of fruits (as this pattern did not occur for thorns; Włodarczyk et al., 2018; 2020) or can be generalized to a broader class of features within plants (e.g., flowers).

\subsection{Sensitivity to social information about plant foods}

Given the importance of social learning in the food context, we predicted that cues of food processing would affect infants' behavior toward plant foods. Specifically, we predicted that (a) cues of food processing would reduce infants' avoidance of processed plant foods relative to whole plants, (b) infants would differentially seek out social information when confronted with processed plant foods, as they do for whole leafy plants, and (c) increasing cues of food processing would reduce infants' reluctance to touch plant foods, such that infants 
should reach more quickly for cut plant foods than picked plant foods. Our results provide some support for these predictions.

First, our results indicate that social information conveyed by cues of plant food processing (i.e., picking and cutting) reduces infants' reluctance to touch plant parts. Infants were less avoidant of the processed plant foods than the whole leafy plants. This finding suggests that signs of previous human engagement (e.g., fruits and leaves that have been picked from their plants, fruits that have been cut) signal to infants that these plant parts are safer to touch, although still not as safe as starchy foods. Our results are in line with recent evidence that watching an adult touch plants reduces infants' plant avoidance behaviors (Włodarczyk et al., 2020) but go further by suggesting that it is not necessary for infants to directly witness the contact. Instead, infants seem to view cues of food processing as a sign of human engagement, similar to adults and young children who see transformed foods (e.g., foods that have been cooked) as manmade objects that bear markers of previous human intervention (Foroni, Pergola \& Rumiati, 2013; Girgis \& Nguyen, 2020; Lafraire, Rioux, Hamaoui, Girgis, Nguyen \& Thibaut, 2020).

Our results are consistent with the existing literature showing that infants selectively use social cues to guide their eating behavior (Addessi et al., 2005; DeJesus et al., 2018; Liberman et al., 2016; Lumeng et al., 2008; Wertz \& Wynn, 2014b, 2019), and to our knowledge, constitute the first evidence of sensitivity to social information conveyed by cues of food processing in infancy. Nevertheless, we did not find differences in infants' reaching behavior for picked and cut plant foods. This result diverges from our original prediction and suggests that infants do not necessarily make fine-grained distinctions between different cues of human intervention when gauging whether a plant part is safe to touch. It seems the important information for infants' reaching decisions is that someone has touched the plant part in the past, not how they touched it. 
While our current results are consistent with the proposal that infants use cues of food processing to guide their behavior toward plant foods, there is much that remains to be investigated. Future studies will be necessary to investigate in detail how infants conceptualize processed food items and what social information is required to fully overcome plant food avoidance. For example, infants in our study seemed to view the plant foods as being safer to touch, but it is unclear whether they viewed the plants as food items. Infants seem not to view plants as edible until they see social information indicating that a plant can be eaten (Wertz \& Wertz, 2014b, 2019). It remains unclear from our dataset whether cues of food processing like picking and cutting are viewed as a signal of edibility per se. Infants did occasionally put the picked and cut fruits in their mouths, but these behaviors were rare (see SM Section 2.3). Additionally, many plant resources are not edible until they undergo more complex processing techniques like grinding, soaking, and cooking (e.g., Mombo et al.2016; Timbrook, 2007; Wrangham, 2009), so evidence of these kinds of human interventions may be more reliable signals that a plant part is edible. It is also an open question whether directly witnessing an adult engaging in the processing steps might reduce infants' reluctance behaviors toward plant foods further. In the current study, infants did not witness the acts of picking or cutting the plant foods. Instead, they were presented with stimuli that bore the signs of previous human engagement. Therefore, these results provide an important baseline measure for future studies that show infants an actor actively processing different types of food (e.g., cutting whole plants with a knife or picking fruits from a leafy plant) and expose them to a broader array of processing outcomes (e.g., cooked foods or pureed foods).

Finally, our social looking results underscored the importance of social information about plants and plant foods. Infants exhibited the most social looking before touching whole plants (both the leafy plants and plants with fruits) replicating and extending previous findings (Elsner \& Wertz, 2019). Infants in our study also engaged in more social looking for processed 
plant foods than starchy foods, although still to a lesser degree than for whole plants. These results are similar to the findings from the food neophobia literature showing that young children are reluctant to eat fruits and vegetables and are sensitive to social information about these food objects (Rioux, 2019). Interestingly, although infants' reaching behavior did not differ across the three types of processed plant foods (picked leaf bouquets, picked fruits, and cut fruits), infants engaged in more social looking for the picked leaf bouquets than the other two items. In fact, the increase in social looking for this category was driven by infants' behavior for the picked leaf bouquets.

The differences we observed in social looking behavior may be because infants and young children are especially inclined to engage in social looking when confronted with ambiguous situations (e.g., Feinman, 1982) and social looking is an active communicative behavior allowing infants to resolve epistemic uncertainty in social learning contexts (Bazhydai et al., 2020; Hembacher et al., 2017). Whole plants may be viewed as, in some sense, more ambiguous because they can be food sources, but they also can be deadly poisonous, and put to many uses outside of the food context (e.g., medicines, raw material for building shelters and artifacts, etc.; Hardy \& Kubiak-Martens, 2016). In contrast, processed plant foods might be less ambiguous to infants because their preparation signals previous human intervention (Girgis \& Nguyen, 2020) and perhaps their intended use in a food context. Consistent with this proposal, infants in the present study sometimes put the processed plant foods in their mouths, but never did this with the whole plants. Interestingly, even within the processed plant food category, infants attempted to eat all of the picked and cut fruits and vegetables, but not the leaf bouquets, mirroring the social looking results. Future studies that are better designed to assess infants' eating behavior (e.g., by not taking the stimuli away immediately after the first touch as we did here) can better address this proposal. 


\subsection{Plant food avoidance in infancy and food neophobic behaviors in toddlerhood}

The current results suggest some relationship between plant food avoidance behaviors in infancy and food neophobic behaviors measured in the same participants approximately one year later. In the older age group (10-15 months of age), infants who displayed higher behavioral avoidance of cut fruits and vegetables were more likely to exhibit greater food neophobia in toddlerhood (as measured by the CFRS; Rioux et al., 2017). In the same vein, the older infants who looked more toward adults when confronted with plant foods were marginally more likely to be neophobic in toddlerhood. In contrast, infants' latency to touch and social looking behaviors for starchy food items that are not targets of food neophobia (Cole et al., 2017), were not predictors of later food neophobic behaviors. None of the younger infants' behaviors toward plant foods were related to later food neophobic behaviors. These findings converge with recent longitudinal data showing that lower levels of approach behaviors toward new foods by older infants (12-month-olds) but not younger infants (6-month-olds) were related to later food neophobia (Moding \& Stifter, 2016a; 2016b; 2018). Our results suggest that infants' avoidance behaviors toward some types of food are more predictive than others. However, given the exploratory nature of our analysis with the reduced sample size and the high general variability with infants, these results should be regarded with caution. No firm conclusions should be drawn at this point as further testing is required to assess the robustness of our findings. Nevertheless, we believe these results provide a promising basis for future research on the development of food neophobia in infancy.

Future research could, for example, examine why infants' behavior toward cut fruits, but not other processed plant foods, was related to later food neophobia. One possible explanation is methodological. The food neophobia questionnaire we used asked parents about food behaviors during meals (e.g., "My child separates the food on their plate“; Rioux et al., 2017; a common feature of food neophobia questionnaires, e.g., Pliner, 1994; Wardle, Guthrie, 
Sanderson \& Rapoport, 2001). Meal time is a context in which toddlers are typically presented with cut (or pureed) food items rather than whole food items, which may account for stronger correlation between infants' latency to touch cut fruits and vegetables and CFRS scores one year later. Another possible explanation is conceptual. It may indeed be the case that, when it comes to later food neophobia, there is something special about infants' behavior toward cut foods. Our behavioral results suggest that cues of food processing (picking and cutting) signal that plant parts are safe to touch (as does watching an adult touch plants; Włodarczyk et al.2020). Yet infants might only view plant parts as edible once they have been cut up (or if they watch an adult taste them, as has been previously found; Wertz \& Wynn, 2014b; 2019). Infant's eating behaviors in this study speak in favor of this explanation since infants put cut food items in their mouths twice as often as whole food items. This would explain why we only saw a significant correlation between infants' behavior toward cut fruits and later food rejection behaviors. Future research could use longitudinal assessments that target foods at different stages of processing (including picked food and purees) to examine these two possibilities--and others--in detail.

If future research bears these findings out, they would have implications for the literature on infants' plant avoidance (e.g., Wertz, 2019). Similar avoidance behaviors towards whole leafy plants and plant parts (picked and cut leaves and fruits) in infancy suggest that plant avoidance behaviors and food neophobia may be overlapping protective strategies. However, the absence of a relationship between infants' latency to touch whole leafy plants, picked leaves and fruits, and later food neophobia suggests that these strategies may be somewhat distinct, even if both strategies may be ultimately motivated by an avoidance of plant toxins (e.g., Cashdan, 1994; 1998; Rioux, 2019; Wertz, 2019; Wertz \& Wynn, 2014a). This finding highlights that the adaptive problems humans face with respect to plants are not limited to food selection. Humans only eat a small proportion of the available plants in the environment, but 
still need to avoid harm from plants that are used for purposes other than food, and minimize contact with irritating excreting toxins and mechanical plant defenses like thorns and stinging hairs, in addition to avoiding the ingestion of toxic plant chemicals (see Wertz, 2019; Wertz \& Wynn, 2014a; Włodarczyk et al., 2018 for details of this argument).

\subsection{Limitations and future directions}

There were several limitations to the current study. First, we did not measure infants' hunger level during the behavioral testing session. Satiety can influence neophobic behaviors and the way adults categorize food (Pliner, Eng \& Krishnan, 1995; de Leeuw \& Todd, 2013). It is unclear what effect satiety might have on neophobic behaviors in infancy, and future studies investigating possible precursors of food neophobia in infancy could include a measure of infants' hunger level. Second, the sample size of the present study was rather small $(\mathrm{N}=56)$ compared to studies of food neophobia in childhood. However, this sample size is typical for, if not slightly larger than, the previous studies investigating behavioral avoidance of plants in infancy and replicated the main findings: infants are reluctant to touch whole plants and look more often toward adults prior to touching whole plants (Elsner \& Wertz, 2019; Wertz \& Wynn, 2014a; Włodarczyk, et al, 2018, 2020). Notably the work presented in the current manuscript is also the first replication of the finding that infants look longer to adults when confronted with whole plants. These replications are particularly valuable given the current replication crisis in our field and underscore the ability of the time-to-touch methodology to yield robust and convergent findings across a series of experiments using a variety of different stimuli. Nevertheless, future studies could employ larger sample sizes, particularly to facilitate longitudinal measurements of food neophobic behaviors from infancy through early childhood.

Finally, we cannot be certain that all infants in our study viewed the food stimuli as potentially edible items, especially because these stimuli were chosen to be unfamiliar to 
infants. Our observations of mouthing behaviors during the study showed that infants brought these items to their mouths more often, suggesting that they saw the food stimuli as edible. However, these mouthing behaviors were relatively rare and, given the limits of infants' attention during the testing session, we did not perform a categorization task. Future studies should investigate how infants categorize plants and plant food items, and test whether these categorization rules are similar to, or different from, categorization rules for other types of food items.

\subsection{Conclusion}

The current work demonstrates that there is much to be gained by exploring the roots of food avoidance behaviors in infancy. Amid the growing concern over the lack of diversity in children's diets, and in particular a paucity of fruits and vegetables, understanding the relationship between plant food avoidance in infancy, social signals of food safety (such as cues of food processing), and later food neophobic behaviors is a critical step towards developing more effective interventions to increase the intake of healthy foods early in life (Rioux, Lafraire \& Picard, 2018). 


\section{References}

Addessi, E., Galloway, A. T., Visalberghi, E., \& Birch, L. L. (2005). Specific social influences on the acceptance of novel foods in 2-5-year-old children. Appetite, 45(3), 264-271. https://doi.org/10.1016/j.appet.2005.07.007

Bates, D., Mächler, M., Bolker, B., \& Walker, S. (2014). fitting linear mixed-effects models using lme4. 1406, arXiv preprint arXiv5823

Bazhydai M., Westermann G., \& Parise E. (2020). "I don't know but I know who to ask": 12month-olds actively seek information from knowledgeable adults. Developmental Science, e12938. https://doi.org/10.1111/desc.12938

Birch, L. L. (1980). Effects of Peer Models' Food Choices and Eating Behaviors on Preschoolers' Food Preferences. Child Development, 51(2), 489. https://doi.org/10.2307/1129283

Boyd, R., Richerson, P., 1985. Culture and the Evolutionary Process. University of Chicago Press, Chicago.

Bretz, F., Hothorn, T., \& Westfall, P. (2010). Multiple Comparisons Using R, CRC Press, Boca Raton

Cashdan, E. (1994). A sensitive period for learning about food. Human Nature, 5(3), 279-291. http://doi.org/10.1007/BF02692155

Cashdan, E. (1998). Adaptiveness of food learning and food aversions in children. Social Science Information, 37(4), 613-632. https://doi.org/10.1177/053901898037004003

Cipollini, M. L., \& Levey, D. J. (1997). Secondary metabolites of fleshy vertebrate-dispersed fruits: adaptive hypotheses and implications for seed dispersal. The American Naturalist, 150(3), 346-372. https://doi.org/10.1086/286069 
Cipollini, M. L., \& Levey, D. J. (1997). Why are some fruits toxic? Glycoalkaloids in solanumand fruit choice by vertebrates. Ecology, 78(3), 782-798. https://doi.org.10.2307/2266058

Cole, N. C., An, R., Lee, S.-Y., \& Donovan, S. M. (2017). Correlates of picky eating and food neophobia in young children: a systematic review and meta-analysis. Nutrition Reviews, 75(7), 516-532. https://doi.org/10.1093/nutrit/nux024

Datavyu Team (2014). Datavyu: A Video Coding Tool. Databrary Project, New York University. URL http://datavyu.org.

DeJesus, J. M., Kinzler, K. D., \& Shutts, K. (2018). Food Cognition and Nutrition Knowledge. In Pediatric Food Preferences and Eating Behaviors (pp. 271-288). https://doi.org/10.1016/B978-0-12-811716-3.00014-2

de Leeuw, J. R., \& Todd, P. M. (2013). The influence of hunger on categorical perception of food and non-food items. Presented at the 3rd Annual Midwest Cognitive Science Conference, Columbus, $\mathrm{OH}$.

Dovey, T. M., Staples, P. A., Gibson, E. L., \& Halford, J. C. G. (2008). Food neophobia and "picky/fussy" eating in children: A review. Appetite, 50(2-3), 181-193. https://doi.org/10.1016/j.appet.2007.09.009

Draper, P., Cashdan, E., 1988. Technological change and child behavior among the !Kung. Ethnology 27 (4), 339-365.

Dunn, K., \& Bremner, J. G. (2017). Investigating looking and social looking measures as an index of infant violation of expectation. Developmental Science, 20(6), e12452. https://doi.org/10.1111/desc. 12452

Elsner, C., \& Wertz, A. E. (2019). The seeds of social learning: Infants exhibit more social looking for plants than other object types. Cognition, 183, 244-255. https://doi.org/10.1016/j.cognition.2018.09.016 
Feinman, S. (1982). Social referencing in infancy. Merrill-Palmer Quarterly, 28, 445-470. https://www.jstor.org/stable/23086154

Foroni, F., Pergola, G., \& Rumiati, R. I. (2013). Food color is in the eye of the beholder: the role of human trichromatic vision in food evaluation. Scientific Reports, 6, http://dx.doi.org/10.1038/srep37034

Gartstein, M. A., \& Rothbart, M. K. (2003). Studying infant temperament via the revised infant behavior questionnaire. Infant Behavior \& Development, 26(1), 64-86. https://dx.doi.org/10.1016/S0163-6383(02)00169-8

Gelman, S. A. (2013). Artifacts and essentialism. Review Philosophy Psychology, 4(3), 449463. https://doi.org/ 10.1007/s13164-013-0142-7.

Girgis, L., \& Nguyen, S. (2020). Grown or Made? Children's Determination of the Origins of Natural versus Processed Foods. Cognitive Development. 56. http://dx.doi.org/10.1016/j.cogdev.2020.100887

Gutheil, G., Bloom, P., Valderrama, N., \& Freedman, R. (2004). The role of historical intuitions in children's and adults' naming of artifacts. Cognition, 91(1), 2342. https://doi.org/10.1016/S0010-0277(03)00165-3

Martens, K. L. (Eds.). Wild harvest: Plants in the hominin and pre-agrarian human worlds. Oxbow Books.

Hardy, K., Kubiak-Martens, L., 2016. Wild Harvest : Plants in the Hominin and pre-Agrarian Human Words. Oxbow Books, Oxford.

Harris, D. R. \& Hillman, G. C., Eds. (1989). Foraging and farming: The evolution of plant exploitation. Vol. 31. New York: Routledge.

Hembacher, E., deMayo, B., \& Frank, M. C. (2017). Children's social referencing reflects sensitivity to graded uncertainty. In Proceedings of the 39th Annual Conference of the Cognitive Science Society, London, UK 
Hewlett, B.S., Lamb, M.E., 2005. Hunter-Gatherer Childhoods: Evolutionary, Developmental, and Cultural Perspectives. Transaction Publishers, Piscataway, NJ.

Kaplan, H., Hill, K., Lancaster, J., Hurtado, A.M., 2000. A theory of human life history evolution: diet, intelligence, and longevity. Evolutionary Anthropology 9 (4), 156-185. https://doi.org/10.1002/1520-6505(2000)9:4<156::AID-EVAN5>3.0.CO;2-7

Kelemen, D., Seston, R., \& Saint Georges, L. (2012) The Designing Mind: Children's Reasoning About Intended Function and Artifact Structure. Journal of Cognition and Development, 13(4), 439-453, https://doi.org/10.1080/15248372.2011.608200

Kubiak-Martens, L. (Eds.), Wild Harvest: Plants in the Hominin and Pre-Agrarian Human World. Oxbow Books

Lafraire, J., Rioux, C., Hamaoui, J., Girgis, H., Nguyen, S., \& Thibaut, J-P. (2020). Food as a borderline domain of knowledge: The development of domain-specific inductive reasoning strategies in young children. Cognitive Development, 56. https://doi.org/10.1016/j.cogdev.2020.100946

Lafraire, J., Rioux, C., Giboreau, A., \& Picard, D. (2016). Food rejections in children: Cognitive and social/environmental factors involved in food neophobia and picky/fussy eating behavior. Appetite, 96, 347-357. https://doi.org/10.1016/j.appet.2015.09.008

Laureati, M., Bergamaschi, V., \& Pagliarini, E. (2014). School-based intervention with children. Peer-modeling, reward and repeated exposure reduce food neophobia and increase liking of fruits and vegetables. Appetite, 83, 26-32. https://doi.org/10.1016/j.appet.2014.07.031

Liberman, Z., Woodward, A. L., Sullivan, K. R., \& Kinzler, K. D. (2016). Early emergingsystem for reasoning about the social nature of food. Proceedings of the National Academy of Sciences, 113, 9480-9485. 
Lo, S., \& Andrews, S. (2015). To transform or not to transform: using generalized linear mixed models to analyse reaction time data. Frontiers in Psychology, 6. https://doi.org/10.3389/fpsyg.2015.01171

Lumeng J. C., Cardinal T. M., Jankowski M., Kaciroti N., \& Gelman S. A. (2008). Children's use of adult testimony to guide food selection. Appetite, 51(2), 302-310. https://doi.org/10.1016/j.appet.2008.03.010

Mennella J. A., Lukasewycz, L. L., Castor, S. M., \& Beauchamp, G. K. (2011). The timing and duration of a sensitive period in human flavor learn a randomized trial. American Journal of Clinical Nutrition, 93(5), 1019-1024. https://doi.org/10.3945/ajcn.110.003541

Mensink, G. B. M., \& Burger, M. (2004). Was isst du? Bundesgesundheitsblatt Gesundheitsforschung - $\quad$ Gesundheitsschutz, 47(3), 219-226. https://doi.org/10.1007/s00103-003-0794-z

Mithöfer, A., \& Boland, W. (2012). Plant defense against herbivores: Chemical aspects. Annu. Rev. Plant. Biol. 63, 431-450. https://doi.org/10.1146/annurev-arplant-042110-103854

Moding, K. J., \& Stifter, C. A. (2016a). Stability of food neophobia from infancy through early childhood. Appetite, 97, 72-78. https://doi.org/10.1016/j.appet.2015.11.016

Moding, K. J., \& Stifter, C. A. (2016b). Temperamental approach/withdrawal and food neophobia in early childhood: Concurrent and longitudinal associations. Appetite, 107, 654-662. https://doi.org/10.1016/j.appet.2016.09.013

Moding, K. J., \& Stifter, C. A. (2018). Does temperament underlie infant novel food responses?: Continuity of approach-withdrawal from 6 to 18 Months. Child Development, 89(4), e444-e458. https://doi.org/10.1111/cdev.12902

Mombo, S., Dumat, C., Shahid, M., \& Schreck, E. (2017). A socio-scientific analysis of the environmental and health benefits as well as potential risks of cassava production and 
consumption. Environmental Science and Pollution Research, 24(6), 5207-5221. https://doi.org/10.1007/s11356-016-8190-z

Monteiro, C. A. (2009). Nutrition and health. The issue is not food, nor nutrients, so much as $\begin{array}{llll}\text { processing. } \quad \text { Public } & \text { Health }\end{array}$ https://doi.org/10.1017/S1368980009005291

Nicklaus, S., \& Monnery-Patris, S. (2018). Food neophobia in children and its relationships with parental feeding practices/style. In Food Neophobia (pp. 255-286). https://doi.org/10.1016/B978-0-08-101931-3.00013-6

Oña, L., Oña, L. S., \& Wertz, A. E. (2019). The evolution of plant social learning through error minimization. Evolution \& Human Behavior, 40(5), 447-456. https://doi.org/10.1016/j.evolhumbehav.2019.05.009

Pliner, P. (1994). Development of measures of food neophobia in children. Appetite, 23, 147163. https://doi.org/10.1006/appe.1994.1043

Pliner, P., Eng, A., \& Krishnan, K. (1995). The effects of fear and hunger on food neophobia in humans. Appetite, 25(1), 77-87. https://doi.org.10.1006/appe.1995.0042

Prell, C., \& Koletzko, B. (2016). Breastfeeding and Complementary Feeding. Deutsches Aerzteblatt Online. https://doi.org/10.3238/arztebl.2016.0435

Putnam, S. P., \& Stifter, C. A. (2002). Development of approach and inhibition in the first year: parallel findings from motor behavior, temperament ratings and directional cardiac response. Developmental Science, $\quad 5(4), \quad$ 441451. https://doi.org/10.1111/14677687.00239

Rioux, C. (2019). Food neophobia in childhood. In H. L. Meiselman (Ed). Handbook of Eating and Drinking: Interdisciplinary Perspectives. Springer Press.

Rioux, C., Lafraire, J., \& Picard, D. (2017a). The Child Food Rejection Scale: Development and validation of a new scale to assess food neophobia and pickiness among 2- to 7-year- 
old French children. Revue Européenne de Psychologie Appliquée/European Review of Applied Psychology, 67(2), 67-77. https://doi.org/10.1016/j.erap.2017.01.003

Rioux, C., Lafraire, J., \& Picard, D. (2018). Visual exposure and categorization performance positively influence 3- to 6-year-old children's willingness to taste unfamiliar vegetables. Appetite, 120, 32-42. https;//doi.org/10.1016/j.appet.2017.08.016

Rioux, C., Picard, D., Lafraire, J., \& Blisset, J. (2019). Food rejection in young children: Validation of the Children Food Rejection Scale in English and cross-cultural examination in the UK and France. Food Quality and Preference, 73, 19-24. https://doi.org/10.1016/j.foodqual.2018.11.018

Rozin, P. (1976). The selection of food by rats, humans and other animals. In J. S. Rosenblatt, R. A. Hinde, E. Shaw, \& C. Beers (Eds.), Advances in the study of behavior (pp. 21-76). New York: Academic Press.

Santhanagopalan, M., Chetty, M., Foale, C., Aryal, S., \& Klein, B. (2018). Modeling neurocognitive reaction time with gamma distribution. Proceedings of the Australasian Computer Science Week Multiconference on - ACSW '18, 1-10. https://doi.org/10.1145/3167918.3167941

Schmitow, C., \& Stenberg, G. (2013). Social referencing in 10-month-old infants. European Journal of Developmental Psychology, 10(5), 533-545. https://doi.org/10.1080/17405629.2013.763473

Shinskey, J. L., \& Munakata, Y. (2005). Familiarity breeds searching: Infant reverse their novelty preferences when searching for hidden objects. Psychological Science, 16, 596600. https://doi.org/10.1111/j.1467-9280.2005.01581.x

Timbrook, J., 2007. Chumash Ethnobotany: Plant Knowledge Among the Chumash People of Southern California. Heyday Books, Berkeley, CA. 
Ungar, P.S., Sponheimer, M., 2011. The diets of early hominins. Science 334 (6053), 190-193. http://dx.doi.org/10.1126/science.1207701.

Wardle, J., Guthrie, C. A., Sanderson, S., \& Rapoport, L. (2001). Development of the Children's Eating Behaviour Questionnaire. Journal of Child Psychology and Psychiatry 42(7), 963-970. https://doi.org/10.1111/1469-7610.00792

Wertz, A. E., \& Wynn, K. (2014a). Thyme to touch: Infants possess strategies that protect them from dangers posed by plants. Cognition, 130(1), 44-49. https://doi.org/10.1016/j.cognition.2013.09.002

Wertz, A. E., \& Wynn, K. (2014b). Selective Social Learning of Plant Edibility in 6- and 18Month-Old Infants. Psychological Science, 25(4), 874-882. https://doi.org/10.1177/0956797613516145

Wertz, A. E., \& Wynn, K. (2019). Can I eat that too? 18-month-olds generalize social information about edibility to similar looking plants. Appetite, 138, 127-135. https://doi.org/10.1016/j.appet.2019.02.013

Wertz, A. E., (2019) how plants shape the mind. Trends in Cognitive Sciences, 23 (7),528-531. https://doi.org/10.1016/j.tics. 2019.04.010.

Wertz, A. E., \& Moya, C. (2019). Pathways to cognitive design. Behavioral Processess, 161, 73-86. https://doi.org/ 10.1016/j.beproc.2018.05.013.

Wrangham, R., 2009. Catching Fire: How Cooking Made Us Human. Basic Books, New York, New York, NY.

Włodarczyk, A., Elsner, C., Schmitterer, A., \& Wertz, A. E. (2018). Every rose has its thorn: Infants' responses to pointed shapes in naturalistic contexts. Evolution and Human Behavior, 39(6), 583-593. https://doi.org/10.1016/j.evolhumbehav.2018.06.001 
Włodarczyk, A., Rioux, C.,, \& Wertz, A. E. (2020). Social information reduces infants ‘ avoidance of plants. Cognitive Development, 54, 100867. https://doi.org/10.1016/j.cogdev.2020.100867

Woodside, J. V., Young, I. S., \& McKinley, M. C. (2013) Fruits and vegetables: measuring intake and encouraging increased consumption. The Proceedings of the Nutrition Society, 7(2), 236-245. https:// doi: 10.1017/S0029665112003059

\section{Supplemental Material}


Running head: Avoidance of plant foods in infancy

\section{Contents of Supplemental Material}

1. Methods

1.1. Stimuli description

1.1.1. Whole plants

1.1.2. Processed plant foods

1.1.3. Controls

1.2. Video set up

1.3. Coding experimenter's behavior

1.4 Parent questionnaires

2. Results

2.1. Infants' reaching behavior

2.1.1. Infants' probability to touch the different stimuli

2.1.2. Infants' latency to touch the different stimuli

2.1.3. Touch frequency to specific parts of the objects (novel artifact and plant with fruits only)

2.1.4. Latency to touch the specific parts of the objects (novel artifact and plant with fruits only)

2.1.5. Descriptives for infants' latency to touch the different stimuli (trials without touches removed)

2.2. Infants' looking behavior

2.2.1. Frequency of social looking

2.2.2. Duration of social looking

2.2.3. Descriptives for infants' proportional social looking

2.3. Infants' eating behavior

2.4. Parent questionnaires

2.5. Follow-up assessment of food neophobia 


\section{Methods}

\subsection{Stimuli description}

\subsubsection{Whole plants}

Leafy plants. The leafy plant stimuli were two plants of different types (fern and dumb cane) made out of plastic or fabric leaves. Similar plant stimuli were used in Elsner and Wertz (2019), Wertz \& Wynn (2014a) and Włodarczyk et al. (2018; 2020). The fern (Fig. 1, Set 1) was made out of plastic stems and measured approximately $23 \mathrm{~cm}$ high by $10 \mathrm{~cm}$ wide. The dumb can (Fig. 1, Set 2) was made from fabric leaves and measured approximately $20 \mathrm{~cm}$ high by $25 \mathrm{~cm}$ wide. Both were arranged in black plastic pots $(8 \mathrm{~cm}$ high by $9 \mathrm{~cm}$ wide) with "pottoppers" that made it look like the plant was growing out of a pot filled with dirt.

Plants with fruits. The plant with fruits stimuli were two leafy plants of different types (daisy and bamboo) made out of plastic or fabric leaves, to which we attached small artificial fruits (lemons and pears). The daisy (Fig. 1, Set 1) was made from fabric leaves and its dimensions approximately matched the dumb cane's measurement. Six artificial green pears of approximately $4 \mathrm{~cm}$ high by $2 \mathrm{~cm}$ wide, were attached to the leaves with green wire. The bamboo (Fig. 1, Set 2) was made of plastic stems and its dimensions approximately matched the fern's measurement. Six artificial yellow lemons of approximately $3 \mathrm{~cm}$ high by $2 \mathrm{~cm}$ wide, were attached to the leaves with green wire. Both were arranged in black plastic pots $(8 \mathrm{~cm}$ high by $9 \mathrm{~cm}$ wide) with "pot-toppers" that made it look like the plant was growing out of a pot filled with dirt. 


\subsubsection{Processed plant foods}

Picked leaf bouquets. The picked leaf bouquet stimuli were two bouquets of different types of leaves (eucalyptus and basil) made out of plastic or fabric. Both were attached together with green raffia to form a bouquet. The eucalyptus leaves (Fig. 1, Set 1) were made of plastic and measured approximately $23 \mathrm{~cm}$ long by $16 \mathrm{~cm}$ wide. The basil leaves (Fig. 1, Set 2) were made of fabric and measured approximately $23 \mathrm{~cm}$ long by $15 \mathrm{~cm}$ wide.

Picked fruits and vegetables. The picked fruit and vegetable stimuli were one fruit (lemon) and one vegetable (Thai eggplant) that infants were not likely to eat at home. The eggplant (Fig. 1, Set 1) was green and approximately $7 \mathrm{~cm}$ long and $4 \mathrm{~cm}$ wide and the lemon (Fig. 1, Set 2) was approximately $8 \mathrm{~cm}$ long and $5 \mathrm{~cm}$ wide. They were bought weekly as to be fresh throughout data collection.

Cut fruits and vegetables. The cut fruit and vegetable stimuli were one fruit (papaya) and one vegetable (bitter cucumber) that infants were not likely to eat at home. The papaya (Fig.1, Set 1) and cucumber (Fig. 1, Set 2) were cut into slices before each session. Only one slice was presented to infants. The slices were approximately $14 \mathrm{~cm}$ long and $4 \mathrm{~cm}$ wide. They were also bought weekly as to be fresh throughout data collection.

\subsubsection{Controls}

Starchy foods. Starchy food items were included to represent a food type that is not a target of food neophobia and provides a benchmark for food behaviors unlikely to be impacted by plant avoidance. The starchy food stimuli were one savory food (raw green pasta) and one sweet food (rice cracker) low in caloric content that infants were not likely to eat at home. The raw green pasta (Fig.1, Set 1) was arranged in a cylinder-shape pile of approximately $7 \mathrm{~cm}$ high and $6 \mathrm{~cm}$ wide, and the yellow rice cracker (Fig.1, Set 2) was approximately $1 \mathrm{~cm}$ high and 9 cm wide. 
Novel artifacts. The novel artifacts were constructed to match features of the whole plants. The first type of artifact matched the overall shape of the whole plant stimuli (see Fig. 1, Set 1$)$. It was made from a yellow cone $(13 \mathrm{~cm}$ high by $6 \mathrm{~cm}$ wide) arranged on top of a cylinder-shaped cardboard base $(5 \mathrm{~cm}$ high, $8 \mathrm{~cm}$ in diameter) painted in black, and wrapped with the same fruits and leaves as the daisy plant but painted in black. The second type of artifact matched the color of the whole plant stimuli (see Fig. 1, Set 2). It was made from a cylinder-shaped cardboard box $(6 \mathrm{~cm}$ high, $7 \mathrm{~cm}$ in diameter) base painted in black and green with large and small popsicles sticks (12 cm long and $2 \mathrm{~cm}$ wide, $5 \mathrm{~cm}$ long and $0.5 \mathrm{~cm}$ wide) protruding from the top and yellow pompoms glued to the sticks $(2 \mathrm{~cm}$ in diameter). Similar stimuli were used in Elsner and Wertz (2019), Wertz \& Wynn (2014) and Włodarczyk et al. $(2018 ; 2020)$.

Naturally occurring objects. The naturally occurring stimuli (shell and natural sponge) were chosen to match the size of the food stimuli and to examine whether infants respond differently to broader classes of naturally occurring objects. The natural sponge (see Fig., 1 Set 1) measured approximately $4 \mathrm{~cm}$ high and $8 \mathrm{~cm}$ wide. The shell (see Fig. 1, Set 2) measured approximately $12 \mathrm{~cm}$ large and $13 \mathrm{~cm}$ wide. Similar stimuli were used in Elsner and Wertz (2019), Wertz \& Wynn (2014a).

\subsection{Video setup}

Infants' behavior during the sessions were recorded on video with four cameras: a front view of the infant and the stimulus object, a side view of the experimenter placing each object in front of the infant, as well as two close-up side views (i.e., left and right) of the object and the infant's hands (see Video S1). Recorded videos were imported into Datavyu (Datavyu Team, 2014) for subsequent behavioral coding. 


\subsection{Coding experimenter's behavior}

In order to assess whether the experimenter's behavior during the object presentation phase may have inadvertently influenced infants, a GoPro Hero 4 recorded the experimenter face in each session. A randomly selected third of the GoPro videos were coded by two independent coders who rated the experimenter's behavior during each trial. The videos were first edited by a third independent research assistant to remove the portion that showed the stimulus object so that the coders were blind to trial type. Based on the experimenter's facial expressions and movements the coders rated the expected object type that was presented (leafy plants, plants with fruits, leaf bouquets, whole fruits and vegetables, cut fruits and vegetables, starchy foods, novel artifacts or naturally occurring objects). A binomial test indicated that the proportion of correctly rated objects was not significantly different from chance (Coder $1=$ $13,48 \%$, Coder $2=12.82 \%$, chance level of $12.50 \%$ given the number of objects in the stimulus set; $p>.05$ for both coders). In addition, the proportion of agreement between the two coders was very low $(9.86 \%)$ and not significantly different from chance level as indicated by a binomial test $(12.50 \%, p=.19)$. This indicates that the experimenter did not exhibit systematically different behaviors across trials.

\subsection{Parent questionnaires}

In order to investigate the potential role of infants' prior experiences and temperament, parents completed a battery of four questionnaires.

The first questionnaire, the Plant Experience Questionnaire (Elsner \& Wertz, 2019; Wertz \& Wynn, 2014a; Włodarczyk et al., 2018) assessed infants’ experience with indoor and outdoor plants during the last months and during the last summer months. Parents were asked: (i) how often their infant interacts with plants, (ii) how often parents point out or name different plants for their infant, (iii) how often their infant sees them caring for plants, (iv) how often 
their infant eats from plants, (v) how often their infant tries to touch plants, (vi) how often they stop their infant from touching plants. Answers were rated on a five-point Likert scale $(1=$ never to $5=$ nearly every day), separately for indoor and outdoor plants as well as two time points (last summer months vs. last month).

Parents filled out a second questionnaire rating the following questions about their infant's experience with the particular stimulus objects: Thai eggplant, lemon, papaya, bitter cucumber, green pasta, rice cracker, natural sponge, and seashell, specifically: (i) whether their infant has ever seen $\mathrm{X}$ (Yes/No), (ii) how often their infant interacts with X, and (iii) how often their infant sees their parent interacting with X. Responses to (ii) and (iii) were rated on a fivepoint Likert scale $(1=$ never to $5=$ nearly every day $)$.

The third questionnaire consisted of three subscales of the Revised Infant Behavior Questionnaire (IBQ-R; Garstein \& Rothbart, 2003): fear (e.g., "How often during the last week did your baby startle to a sudden or loud noise?”), perceptual sensitivity (e.g., "During feeding, how often did your baby notice lumpy texture in food?") and approach (e.g., "How often during the week did your baby move quickly toward new objects?"). Answers were rated on a sevenpoint Likert scale $(1=$ never to 7 = always $)$.

The fourth questionnaire was a Food Frequency Questionnaire (Mensink \& Burger, 2004) that assessed infants' food habits and consumption to examine whether they are associated with infants' reaching behavior toward the stimulus objects, particularly the food stimuli. Parents were asked how often their infant eats 30 typical German foods at home (e.g., eggs, chocolate, cheese, rice, fresh vegetables, meat, etc.). Their responses were rated on a ninepoint Likert scale $(0=$ never to $9=$ more than five times a day $)$. 


\section{Results}

In order to test whether infants exhibit behavioral avoidance of whole plants and processed plant foods and examine their sensitivity to cues of food processing, we assessed infants' reaching behavior toward each stimulus. We also assessed infants' social looking before touching the stimuli to examine whether infants seek social information prior to touching processed plant foods like they do for whole leafy plants. Finally, we assessed the relationship between infants' reaching behavior in this study with their food neophobic behaviors about one year later.

\subsection{Infants' reaching behavior}

\subsubsection{Infants' probability to touch the different stimuli}

In order to test the prediction that infants would avoid touching whole plants and processed plant foods compared to control objects, we first analyzed whether infants were less likely to touch whole plants and processed plant foods than control objects, with a generalized linear mixed-effects model using a Binomial distribution. Infant participants served as a random factor to account for shared variances within subjects, whereas Object Type (whole plants, processed plant foods, starchy foods, novel artifacts, and naturally occurring objects), Order of presentation (continuous factor) and Age (continuous factor) were modeled as fixed effects. For the Object Type variable, we first investigate differences between our five broad categories of interest. We then investigated difference within each category, as objects in one category had different characteristics. We always singled out the control objects in the analysis as previous studies found that infants react differently towards these objects (Elsner \& Wertz, 2019; Wertz \& Wynn, 2014a; Włodarczyk et al., 2020). The results revealed a significant effect of Order of object presentation $\left(\chi 2(1)=11.51, \mathrm{p}=.00069\right.$, marginal pseudo $\left.R^{2}=.02\right)$, indicating that the probability of touching an object increased as the session unfolded. Critically, as predicted, the 
results also revealed a significant effect of Object Type $(\chi 2(7)=22.16, p=.0024$, marginal pseudo $R^{2}=.04$, see Fig. S1). There was no main effect of Age nor an Age x Object Type interaction.

Infants' probability of touching whole plants (leafy plants and plants with fruits, $M=$ $.76, \mathrm{SD}=.43$ ) was lower than touching processed plant foods (picked leaf bouquets, picked and cut fruits and vegetables $\mathrm{M}=.86, \mathrm{SD}=.34, \mathrm{~b}=3.02, \mathrm{SE}=.86, \mathrm{z}=3.52, \mathrm{p}=.00043)$, and controls ( starchy food, $\mathrm{M}=.89, \mathrm{SD}=.31, \mathrm{~b}=2.64, \mathrm{SE}=.83, \mathrm{z}=3.20, \mathrm{p}=.0014$; novel artifacts, $\mathrm{M}=.86, \mathrm{SD}=.35, \mathrm{~b}=3.77, \mathrm{SE}=1.55, \mathrm{z}=2.43, \mathrm{p}=.015 ;$ naturally occurring objects, $\mathrm{M}=.88$, $\mathrm{SD}=.32, \mathrm{~b}=5.32, \mathrm{SE}=1.65, \mathrm{z}=3.22, \mathrm{p}=.0013)$. None of the comparisons within the whole plant, processed plant food or control categories were significant. 
Figure S1. Infants' probability to touch the different stimuli. Error bars depict standard errors.

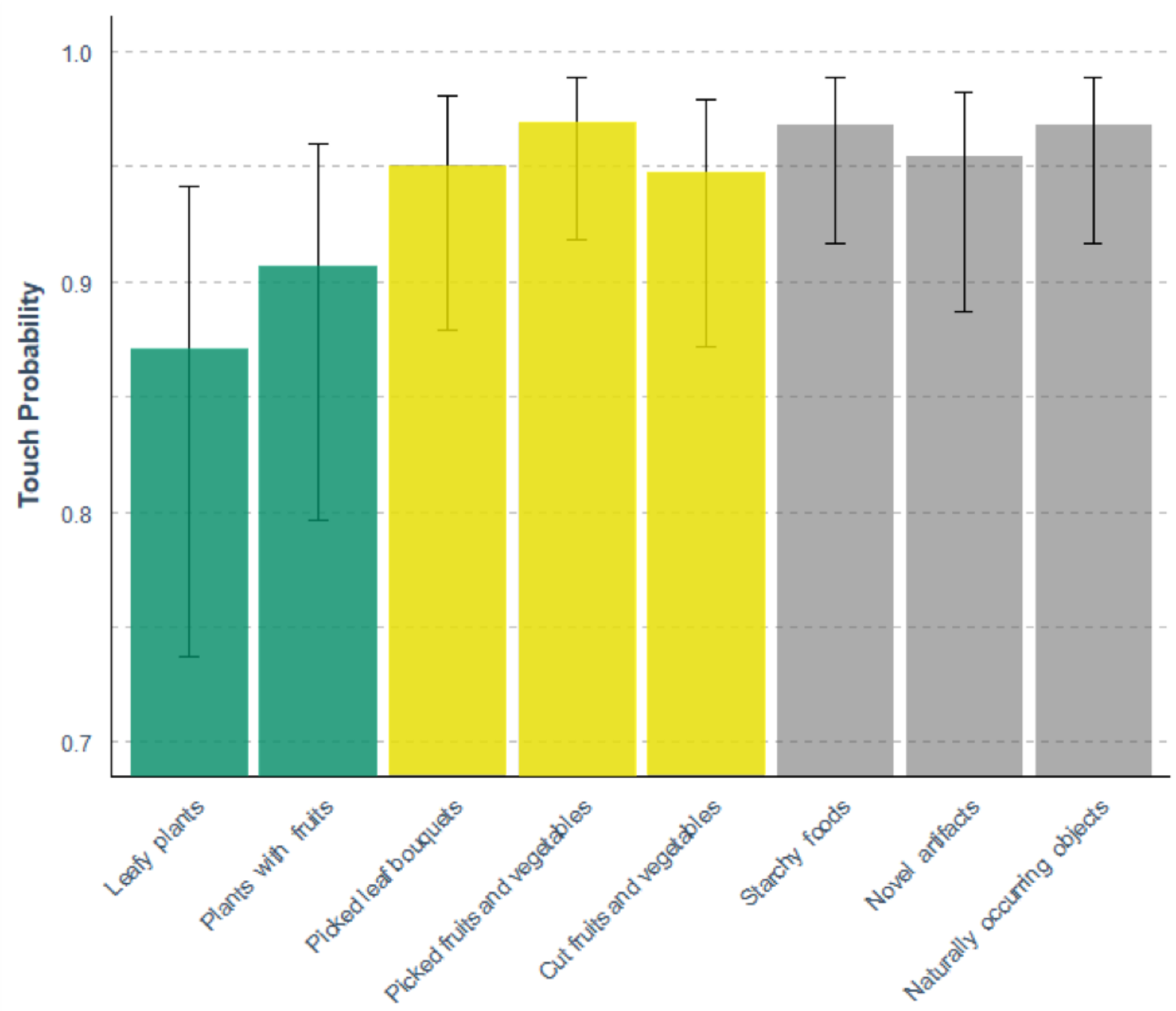

Note. Green bars: Whole plants; Yellow bars: Processed plant foods; Grey bars: Non-plant food controls

\subsubsection{Infants' latency to touch the different stimuli (trials without touches included)}

In order to directly compare with previous studies (Elsner and Wertz, 2019; Wertz \& Wynn, 2014a; Włodarczyk et al., 2018), here we analyzed infants' latency to touch the different stimuli without removing trials with no touches. In this analysis, latency data were logtransformed to correct for non-normality and analyzed with a linear mixed-effects model using a Gaussian distribution as in previous studies. Again, infant participants served as a random 
factor to account for shared variances within subjects, whereas Object Type (whole plants, processed plant foods, starchy foods, novel artifacts, and naturally occurring objects), Order of presentation (continuous factor) and Age (continuous factor) were modeled as fixed effects. The results revealed a significant effect of Order of object presentation $(\chi 2(1)=23.60, p<$ .0001 , marginal pseudo $R^{2}=.02$ ), indicating that the time infants took to touch an object decreases as the session unfold. Importantly, the results also revealed a significant effect of Object Type $\left(\chi 2(7)=31.89, \mathrm{p}<.0001\right.$, marginal pseudo $R^{2}=.02$, see Fig. S2). There was no main effect of Age nor an Age x Object Type interaction.

Infants' latency to touch whole plants overall (leafy plants and plants with fruits, $M=$ 11162.08, $S D=12062.68$ ) was longer than to touch processed plant foods (picked leaf bouquets, picked and cut fruits and vegetables, $M=7617.55, S D=10488.35, b=1.28, S E=$ $.37, z=3.43, p=.00060$ ) and controls (starchy foods $M=6045.13, S D=9746.38, b=1.45, S E$ $=.33, z=4.37, p<.0001$; novel artifacts $M=8653.19, S D=10720.33, b=1.49, S E=.66, z=$ $2.25, p=.025$; naturally occurring objects; $M=5953.88, S D=9548.38, b=2.91, S E=.66, z=$ $4.40, p<.0001)$. Infants' latency to touch processed plant foods was marginally longer than to touch starchy foods $(b=.88, S E=.47, z=1.90, p=.058)$ and naturally occurring objects $(b=$ $.90, S E=.47, z=1.93, p=.053)$. This pattern replicate and extend previous findings, showing that infants are more reluctant to touch whole leafy plants compared to processed plant foods (Elsner and Wertz, 2019; Wertz \& Wynn, 2014a; Włodarczyk et al., 2018; 2020). Within broader categories none of the comparisons were significant. 
Figure S2. Infant's log-latency to touch the different stimuli, including the no-touch trials.

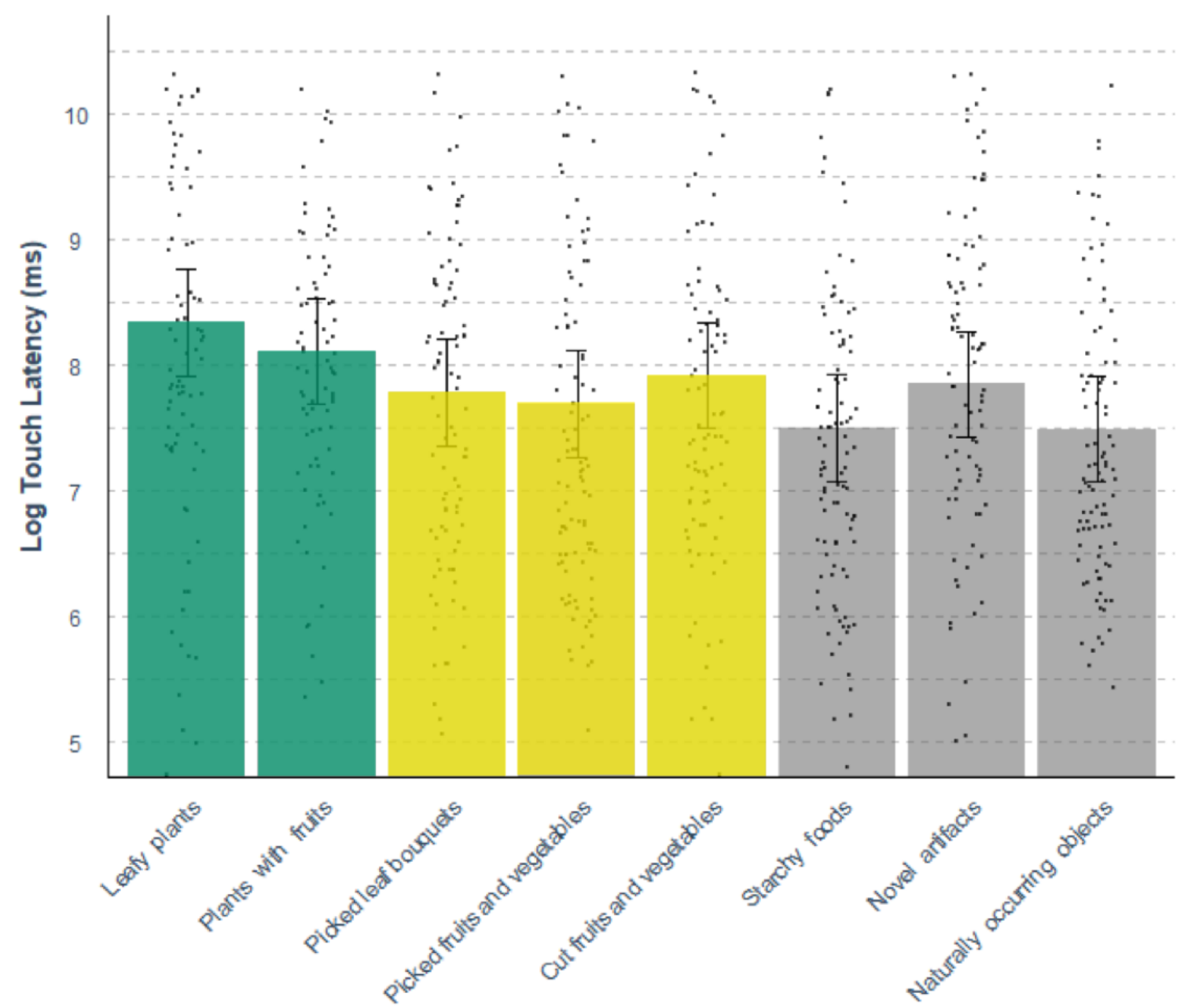

Note. Green bars: Whole plants; Yellow bars: Processed plant foods; Grey bars: Non-plant food controls. Data points represent individual trials. Error bars depict standard errors. Log latency values above $5 \mathrm{~ms}$ for individual trials are reported on the figure. Log latency values above $5 \mathrm{~ms}$ for individual trials are not shown on the figure, resulting in the following number of trials not shown for each stimulus object: Leafy plants (6); Plants with fruits (6); Picked leaf bouquets (4); Picked fruits and vegetables (1); Cut fruits and vegetables (4); Starchy foods (3); Novel artifacts (7); Naturally occurring objects (4). 
2.1.3. Touch frequency to specific parts of the objects (novel artifacts and plants with fruits only)

To investigate the effect of the presence of fruits on whole plants and control objects on infants' manual exploration in more detail, we assessed the effect of Object Type on Touch Frequency to specific parts of the objects (i.e., the number of touches to leaf parts and fruit parts). For this analysis we removed any touch to leaf parts that occurred less than one second before or after a touch to a fruit part. These touches were counted as accidental touches since, to have access to fruit parts, infants had to touch the leaves, especially for the whole plant objects. The data were analyzed using generalized linear models with a Poisson distribution and a correction for over-dispersion due to zero-inflation. In the model, infant participants and an individual variable correcting for over-dispersion were treated as random effects, whereas Object Type (plants with fruits, novel artifacts) and Place of Touch (fruit parts, leaf parts) as within participant fixed-effects.

The results revealed only a significant interaction effect of Object Type x Place of Touch $\left(\chi^{2}(1)=18.46, p<.0001\right.$, marginal pseudo $R^{2}=.07$, see Fig. S3). Infants touched the fruit parts more often $(M=.84, S D=.86)$ than the leaf parts of the novel artifacts $(M=.38, S D$ $=.71, b=.80, S E=.19, z=4.12, p=.00023$ ) but did not show a difference for touching fruits and leaves on plants with fruits $(p>.5)$. Additionally, infants touched fruit parts of novel artifacts more often than fruit parts of plants $(M=.44, S D=.59, b=.65, S E=.19, z=3.3 .5, p$ $=.0022)$. Finally, infants touched the leaves of plants $(M=.65, S D=.94)$ more often than the leaf parts of novel artifacts $(b=.53, S E=.20, z=2.61, p=.036)$. 
Figure S3. Touch frequency to specific parts of the objects. Error bars depict standard errors.

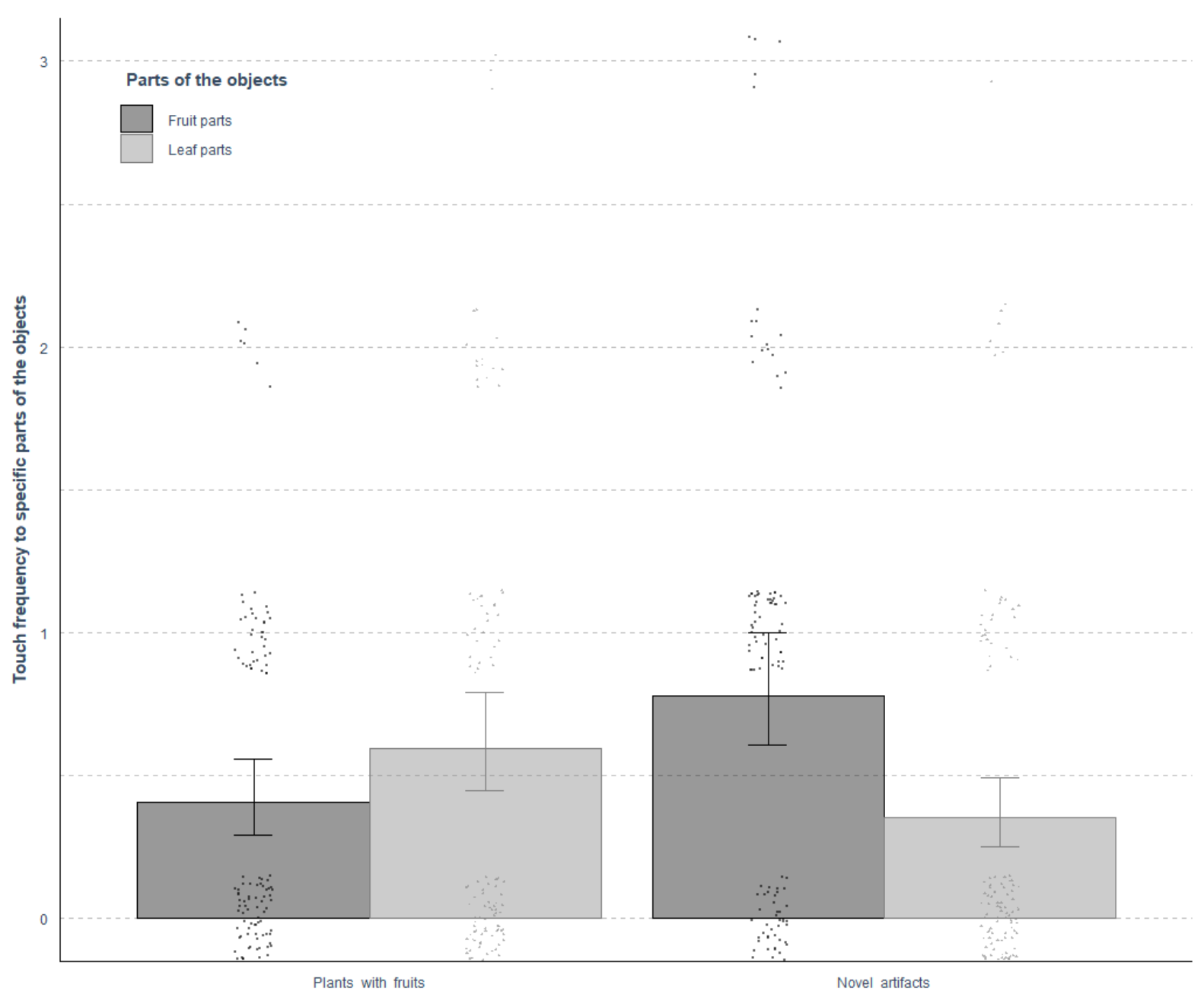

2.1.4. Latency to touch the specific parts of the objects (novel artifacts and plants with fruits only)

To further investigate the effect of the presence of fruits on whole plants and control objects, we assessed the effect of Object Type on Latency to touch the specific parts of the objects (i.e., the latency to touch the leaf and fruit parts). For this analysis we again removed any touch to leaf parts that occurred less than one second before or after a touch to a fruit part. The data were analyzed using generalized linear models with a Normal distribution. In the model, infant participants were treated as random effects, whereas Object Type (plants with fruits, novel artifacts) and Place of Touch (fruit parts, leaf parts) as within participant fixedeffects. 
The results revealed only a significant interaction effect of Object Type x Place of Touch $\left(\chi^{2}(1)=8.25, p=.0041\right.$, marginal pseudo $R^{2}=.04$, see Fig. S4). Infants touched the fruit parts faster $(M=4547.19, S D=5954.64)$ than the leaf parts of the novel artifacts $(M=7342.53, S D$ $=8367.12, b=3093, S E=1131, z=2.74, p=.031)$ but did not show a difference for latency to touch fruits and leaves on plants with fruits $(p>.5)$. Additionally, infants touched leaf parts of novel artifacts faster than leaf parts of plants $(M=3406.27, S D=3825.28, b=3589, S E=$ $1148, z=3.12, p=.011)$.

These results indicate that while infants were more inclined to touch the fruit parts of novel artifacts (they touched them more often and faster), the presence of fruits on whole leafy plants did not influence the pattern of manual exploration within the plants. Further, although infants reached more quickly for plants with fruits than leafy plants without fruits overall (see main text analyses, section 3.1), infants were just as likely to never touch plants with fruits as leafy plants (see above, section 2.1.1) and did not reach faster for fruit parts compared to leaf parts of plants. 
Figure S4. Latency to touch the specific parts of the objects.

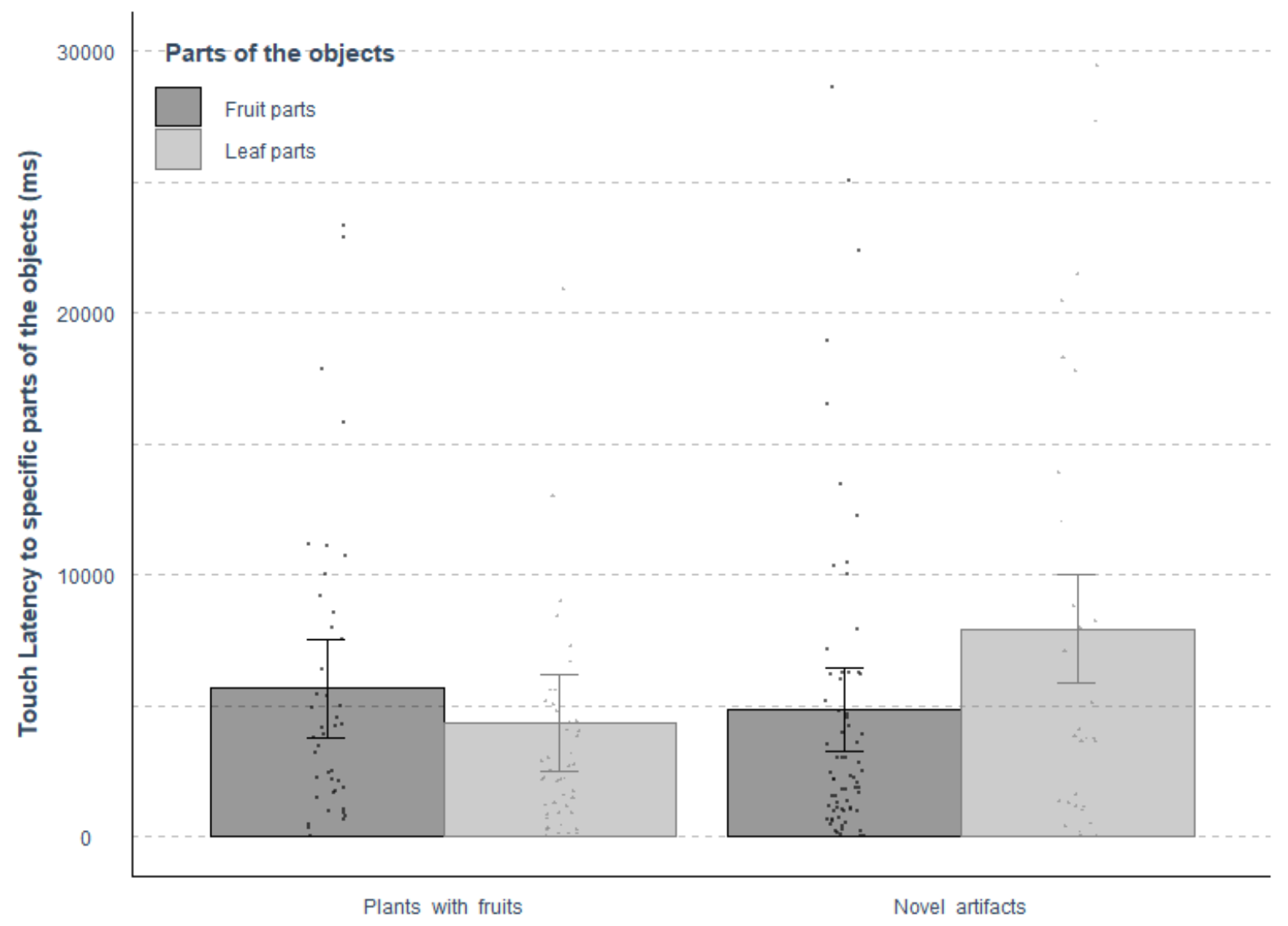

Note. Data points represent individual trials. Error bars depict standard errors. Latency values below $15000 \mathrm{~ms}$ for individual trials are reported on the figure. Latency values above 15000 $\mathrm{ms}$ for individual trials are not shown on the figure, resulting in the following number of trials not shown for each stimulus object: Plants with fruits (5); Novel artifacts (11). 


\subsubsection{Descriptives for infants' latency to touch the different stimuli (trials without touches}

removed)

Table S1. Infants' latency to touch the different stimuli (trials without touches removed).

\begin{tabular}{|c|c|c|c|c|c|c|c|c|c|}
\hline \multicolumn{10}{|c|}{ Latencies (ms) } \\
\hline & Whole plant & & & Processed & plant food & & $\begin{array}{l}\text { Starchy } \\
\text { food }\end{array}$ & $\begin{array}{c}\text { Novel } \\
\text { artifact }\end{array}$ & $\begin{array}{c}\text { Naturally } \\
\text { occurring } \\
\text { object }\end{array}$ \\
\hline $\begin{array}{l}\text { Leafy } \\
\text { plant }\end{array}$ & $\begin{array}{l}\text { Plant } \\
\text { with } \\
\text { fruits }\end{array}$ & Overall & $\begin{array}{l}\text { Picked } \\
\text { leaf } \\
\text { bouquet }\end{array}$ & $\begin{array}{l}\text { Picked } \\
\text { fruit }\end{array}$ & Cut fruit & Overall & & & \\
\hline 6320.89 & 4308.02 & 5296.38 & 4098.24 & 3821.09 & 4274.23 & 4058.50 & 3170.54 & 5095.39 & 2796.31 \\
\hline (8079.07) & (5095.39) & (6731.42) & (5594.00) & (5923.26) & (6243.47) & (5908.06) & $(5348.22)$ & $(6689.00)$ & (4060.98) \\
\hline
\end{tabular}

Note. Numbers in parenthesis are Standard Deviations.

\subsection{Infants' looking behavior}

\subsubsection{Frequency of social looking}

To investigate whether infants engaged in more social looking before touching whole plants and processed plant foods, we examined the frequency of their social looking toward adults before touching each stimulus item. To do this, we used generalized linear models with Poisson distributions and a correction for over-dispersion due to zero-inflation. In the model, infant participants and an individual variable correcting for over-dispersion were treated as random effects, whereas Object Type (whole plants, processed plant foods, starchy foods, novel artifacts, and naturally occurring objects) and Age (continuous factor) were modeled as fixed effects. Due to failure in model convergence, Order of object presentation was not entered in 
the model. The results only revealed a significant effect of Object Type $\left(\chi^{2}(7)=59.81, p<\right.$ .0001 , marginal pseudo $R^{2}=.06$, see Fig. S5).

Infants exhibited more social looks for whole plants (leafy plants and plants with fruits: $M=$ $1.37, S D=1.57$ ) compared to processed plant foods (picked leaf bouquets, picked and cut fruits and vegetables: $M=.82, S D=1.29, b=1.737, S E=.31, z=5.50, p<.0001)$, and two out of the three control objects (starchy foods: $M=.58, S D=.99, b=1.84, S E=.32, z=5.78, p<$ .0001 and naturally occurring objects: $M=.63, S D=1.20, b=3.51, S E=.63, z=5.59, p<$ .0001). Infants also exhibited more social looks for processed plant foods compared to starchy foods $(b=1.02, S E=.47, z=2.17, p=.030)$ and marginally more than for naturally occurring objects $(b=.90, S E=.47, z=1.93, p=.053)$. Finally, infants exhibited more social looks for novel artifacts $(M=1.16, S D=1.59)$ compared to processed plant foods $(b=1.05, S E=.40, z$ $=2.64, p=.0083)$, starchy foods $(b=2.08, S E=.53, z=3.88, p<.0001)$ and naturally occurring objects $(b=2.6, S E=.71, z=3.69, p=.00023)$. These results partly replicate and extend the pattern found in Elsner and Wertz (2019). Within the whole plant category and within the processed plant food category, none of the comparisons were significant. 
Figure S5. Frequency of social looking.

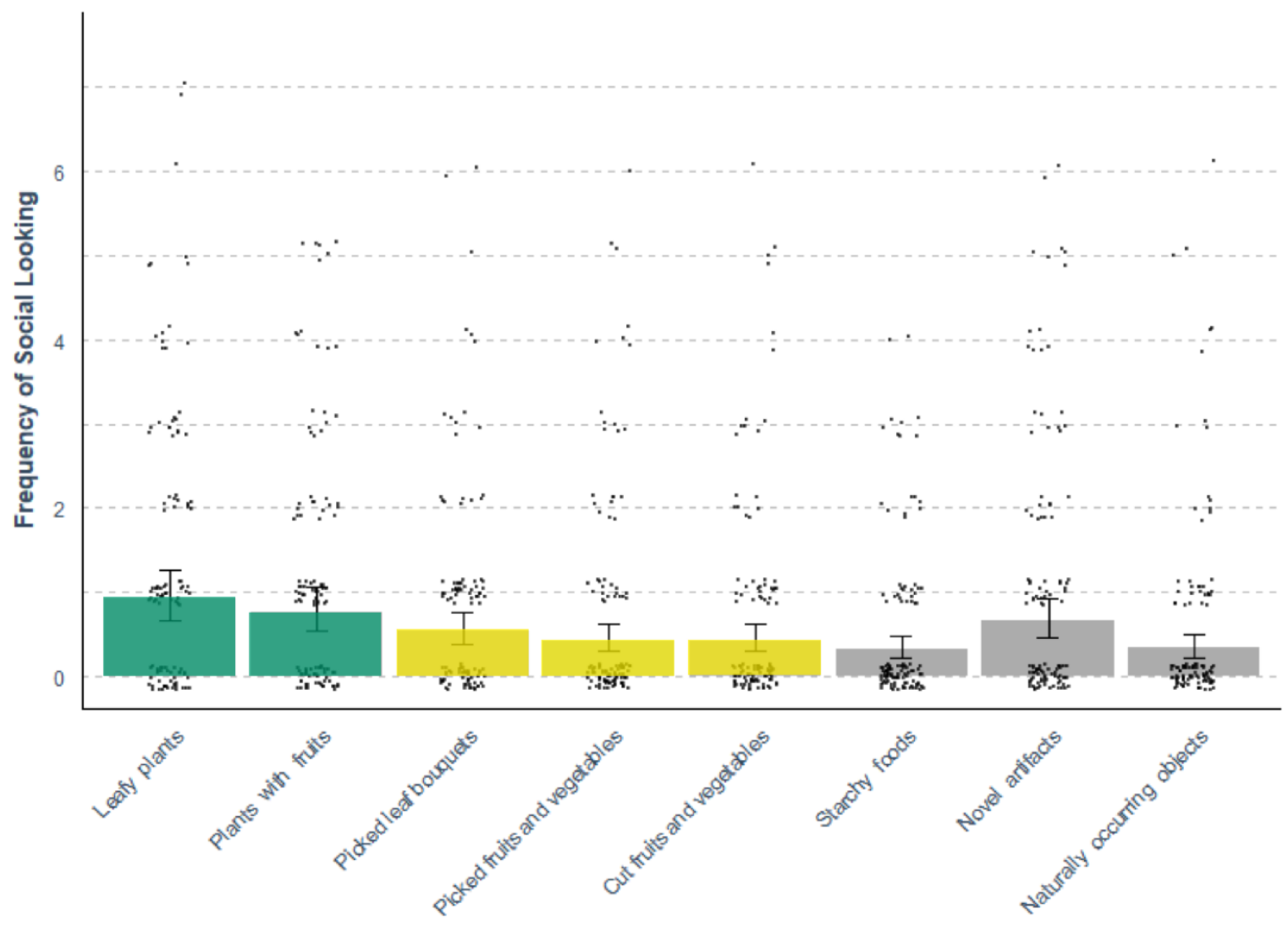

Note. Note. Green bars: Whole plants; Yellow bars: Processed plant foods; Grey bars: Nonplant food controls. Data points represent individual trials. Error bars depict standard errors. Frequency values below 4 for individual trials are reported on the figure. Frequency values above 4 for individual trials are not shown on the figure, resulting in the following number of trials not shown for each stimulus object: Leafy plants (7); Plants with fruits (6); Picked leaf bouquets (3); Picked fruits and vegetables (3); Cut fruits and vegetables (4); Novel artifacts (7); Naturally occurring objects (3). 


\subsubsection{Duration of social looking}

In this analysis, we examined how long infants engaged in social looking, for each object type. Duration values were analyzed with a generalized linear mixed effects model using a Gamma distribution. Infant participants served as a random factor, whereas Object Type (whole plants, processed plant foods, starchy foods, novel artifacts, and naturally occurring objects), Order of presentation (continuous factor) and Age (continuous factor) were modeled as fixed effects. The results revealed a significant effect of Order of object presentation $\left(\chi^{2}(1)\right.$ $=33.60, p<.0001$, marginal pseudo $R^{2}=.01$,), indicating that the time infants spent for social looks decrease as the session unfold. Importantly, the results also revealed a significant effect of Object Type $\left(\chi^{2}(7)=49.619, p<.0001\right.$, marginal pseudo $R^{2}=.02$,see Fig. S6). There was no main effect of Age nor an Age x Object Type interaction.

Infants spent more time in social looking toward adults for whole plants (leafy plants and plants with fruits: $M=2310.92, S D=3346.40$ ) compared to processed plant foods (picked leaf bouquets, picked and cut fruits and vegetables: $M=1211.89, S D=2507.69, b=2.88, S E$ $=.57, z=5.04 p<.0001$ ) and controls (starchy foods: $M=1486.88, S D=2300.89, b=2.51$, $S E=.51, z=4.92, p<.0001$; novel artifact: $M=1486.88, S D=2300.89, b=3.79, S E=1.09$, $z=3.68, p=.00023$ and naturally occurring objects, $M=890.69, S D=1894.40, b=6.06, S E$ $=1.04, z=5.82, p<.0001)$. Infants spent less time in social looking for naturally occurring objects compared to processed plant foods $(b=-1.66, S E=.73, z=2.29, p=.022)$ and novel artifacts $(b=-2.27, S E=1.16, z=1.96, p=.050)$. These results replicate and extend the pattern found in Elsner and Wertz (2019) where they found that infants engaged in longer social looking when confronted with whole leafy plants compared to novel artifacts and naturally occurring objects. Within the whole plant category and within the processed plant food category, none of the comparisons were significant. 
Figure S6. Duration of social looking.

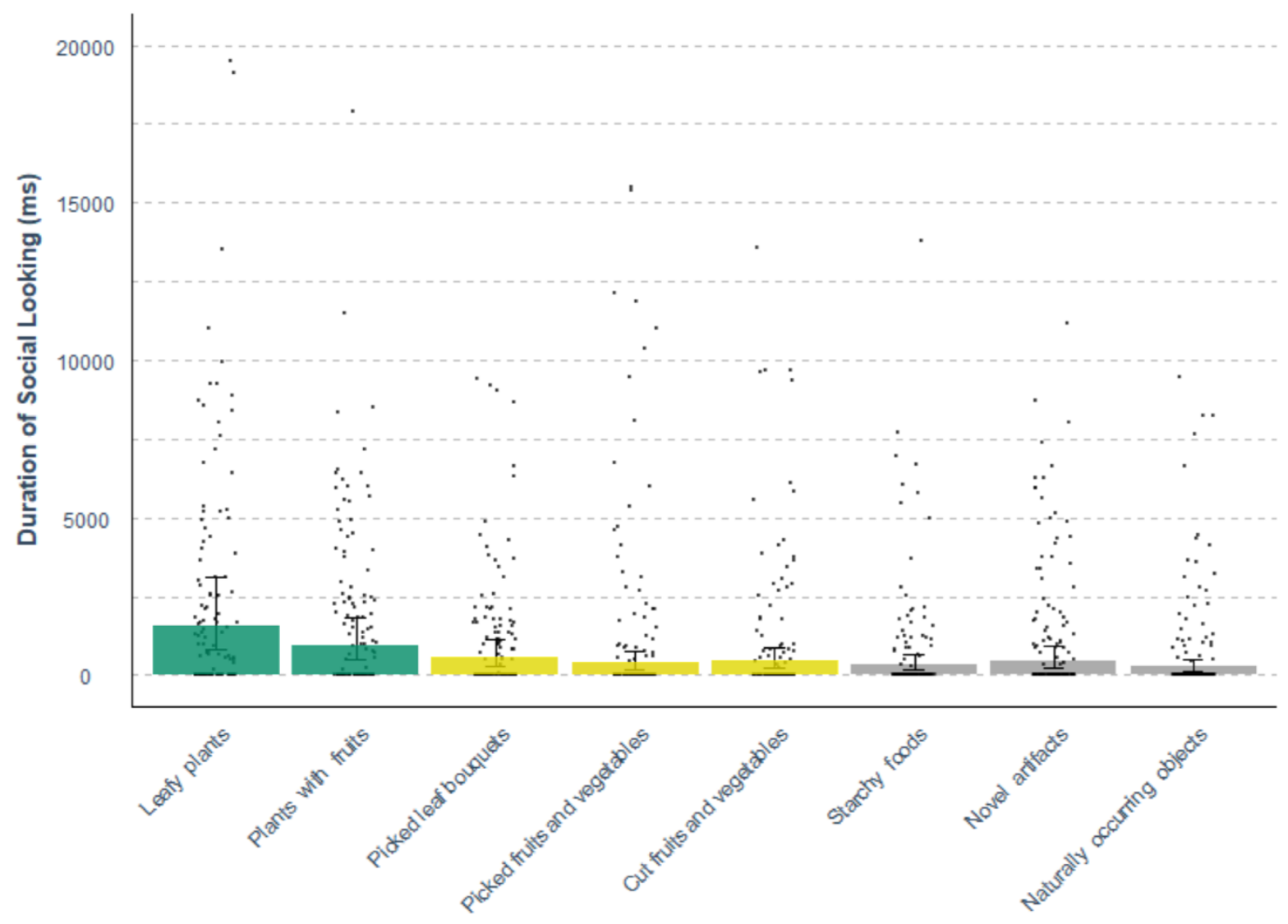

Note. Note. Green bars: Whole plants; Yellow bars: Processed plant foods; Grey bars: Nonplant food controls. Data points represent individual trials. Error bars depict standard errors. Duration values below $7500 \mathrm{~ms}$ for individual trials are reported on the figure. Duration values above $7500 \mathrm{~ms}$ for individual trials are not shown on the figure, resulting in the following number of trials not shown for each stimulus object: Leafy plants (13); Plants with fruits (4); Picked leaf bouquets (4); Picked fruits and vegetables (8); Cut fruits and vegetables (5); Starchy foods (2); Novel artifacts (3). 


\subsubsection{Descriptives for infants' proportional social looking}

Table S2. Infants' proportional social looking.

\begin{tabular}{|c|c|c|c|c|c|c|c|c|c|}
\hline \multicolumn{10}{|c|}{ Proportional Social Looking } \\
\hline \multicolumn{3}{|c|}{ Whole plants } & \multicolumn{4}{|c|}{ Processed plant food } & $\begin{array}{c}\text { Starchy } \\
\text { food }\end{array}$ & $\begin{array}{l}\text { Novel } \\
\text { artifact }\end{array}$ & $\begin{array}{c}\text { Naturally } \\
\text { occurring } \\
\text { object }\end{array}$ \\
\hline $\begin{array}{l}\text { Leafy } \\
\text { plant }\end{array}$ & $\begin{array}{l}\text { Plant } \\
\text { with } \\
\text { fruits }\end{array}$ & Overall & $\begin{array}{l}\text { Picked } \\
\text { leaf } \\
\text { bouquet }\end{array}$ & $\begin{array}{l}\text { Picked } \\
\text { fruit }\end{array}$ & Cut fruit & Overall & & & \\
\hline 11.49 & 11.00 & 11.24 & 7.82 & 6.99 & 5.63 & 6.38 & 5.09 & 8.05 & 5.15 \\
\hline (13.25) & $(12.56)$ & $(12.88)$ & $(9.72)$ & $(12.45)$ & $(9.32)$ & (10.17) & $(8.67)$ & (10.54) & $(9.52)$ \\
\hline
\end{tabular}

Note. Numbers in parenthesis are Standard Deviations.

\subsection{Infant's eating behavior}

In order to examine whether infants saw our food stimuli (picked leaf bouquets, picked and cut fruits, and starchy foods) as potential food items, we assessed infant's mouthing behavior for each object types. Infants never brought the whole plants (leafy and with fruits) nor the novel artifacts to their mouths. Consistent with the idea that infants viewed the foods as being edible, infants put picked fruits to their mouths four times in total, cut fruits eight times and starchy foods five times in total. However, infants also put naturally occurring objects into their mouths four times in total. It is nevertheless important to note that overall mouthing behavior were low since we removed the objects as soon as infants touched them. 


\subsection{Parent questionnaires}

We conducted correlational analyses to examine whether prior experiences and individual difference measures influenced infants' behaviors toward the stimulus objects in this study.

None of the questions assessing infants' prior experiences with plants were related to infants' reaching behaviour, but there were some associations with infants' looking behavior. Parental prohibition of infants touching plants was positively associated with the proportional time infants spent engaging in social looking before touching novel artifacts $(r=.43, p=.0021)$. There was no association between social looking towards whole plants in general and parental prohibition, nonetheless within this category we found that parental prohibition of infants touching plants was positively associated with the proportional time infants spent engaging in social looking before touching plants with fruits $(r=.43, p=.0032)$.

No significant correlations were found between touch latency towards our five categories of interest and infants' temperament. Within the categories, the only significant correlation we found with touch latency was a positive association between infants' level of fear and their latency to touch whole plants with fruits $(r=.46, p=.0066)$. For infants' looking behavior, we found only that proportional social looking before touching starchy foods was positively correlated with infants' level of fear $(r=.40, p=.0025)$.

Tables S3-S9 include all the correlations we ran for Latency and proportional Social Looking. Infants' experiences with plants in the last month and in the last summer months were highly correlated $(.65<r<.99)$, therefore we average these two items to have one score depicting infants' experience in the last several months. We include the Bonferroni corrected alpha used for each table below. Table S10 displays how often infants interacted with the particular stimuli used in the study and how often they sees their parent interacting with them. 
Table S3. Summary of the correlations between infants' experiences with the outdoor and indoor plants in the last several months (12 questionnaire items; corrected alpha level 0.0042) and the latency for the study objects.

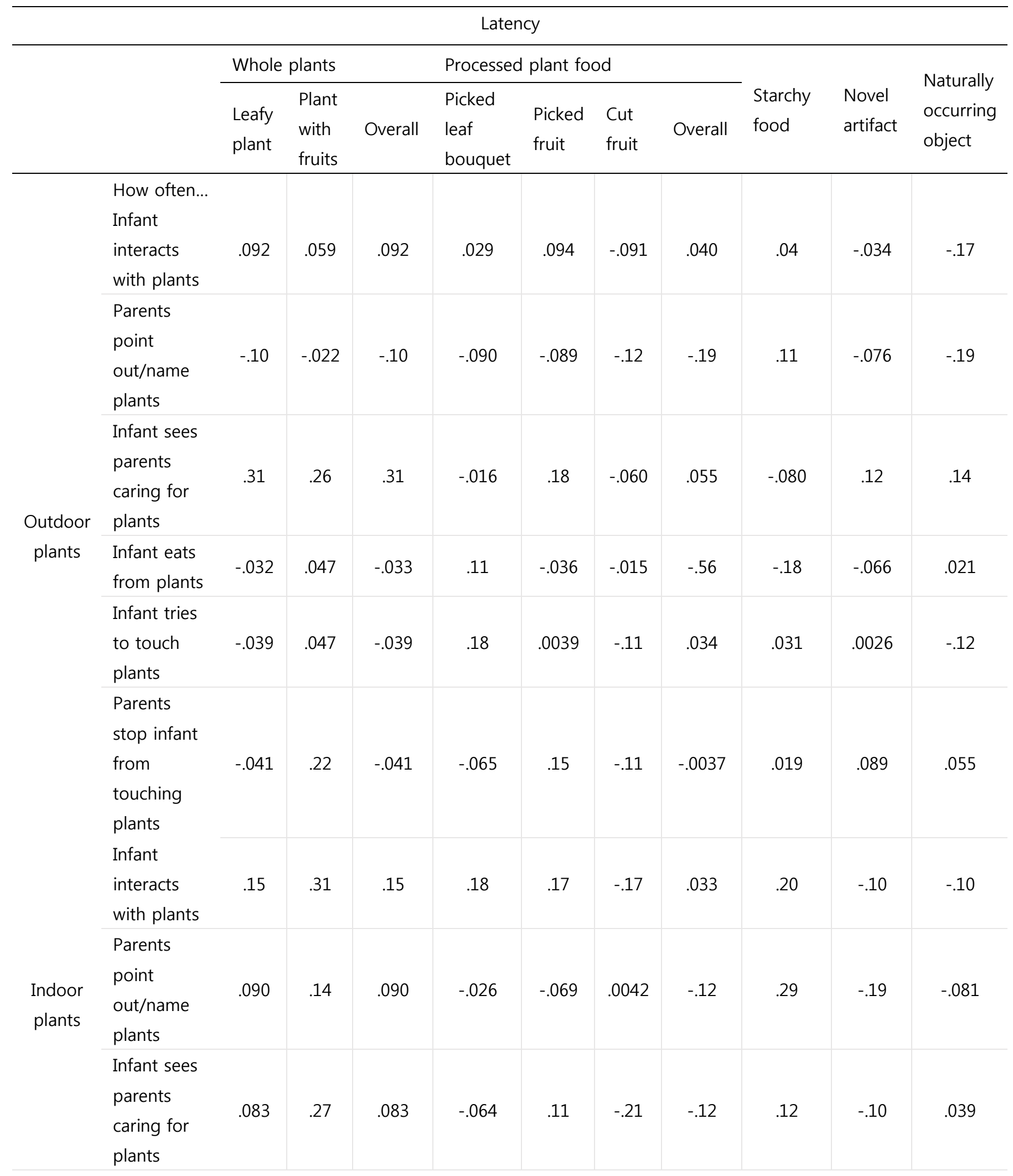


Running head: Avoidance of plant foods in infancy

\begin{tabular}{|c|c|c|c|c|c|c|c|c|c|c|}
\hline $\begin{array}{l}\text { Infant eats } \\
\text { from plants }\end{array}$ & .29 & .065 & .29 & .048 & .29 & $\begin{array}{c}- \\
.0076\end{array}$ & .095 & -.077 & .0065 & .038 \\
\hline $\begin{array}{l}\text { Infant tries } \\
\text { to touch } \\
\text { plants }\end{array}$ & .19 & .30 & .19 & .24 & .16 & -.14 & .075 & .27 & -.023 & .16 \\
\hline $\begin{array}{l}\text { Parents } \\
\text { stop infant } \\
\text { from } \\
\text { touching } \\
\text { plants }\end{array}$ & -.085 & .38 & -.085 & .30 & -.076 & .12 & .14 & .098 & .13 & .18 \\
\hline
\end{tabular}


Running head: Avoidance of plant foods in infancy

Table S4. Summary of the correlations between infants' food consumption at home (4 questionnaire items; corrected alpha level 0.0125) and the latency for the study objects.

\begin{tabular}{|c|c|c|c|c|c|c|c|c|c|c|c|}
\hline \multicolumn{12}{|c|}{ Latency } \\
\hline & & \multicolumn{3}{|c|}{ Whole plants } & \multicolumn{4}{|c|}{ Processed plant food } & \multirow[b]{2}{*}{$\begin{array}{c}\text { Starchy } \\
\text { food }\end{array}$} & \multirow[b]{2}{*}{$\begin{array}{l}\text { Novel } \\
\text { artifact }\end{array}$} & \multirow[b]{2}{*}{$\begin{array}{l}\text { Naturally } \\
\text { occurring } \\
\text { object }\end{array}$} \\
\hline & & $\begin{array}{l}\text { Leafy } \\
\text { plant }\end{array}$ & $\begin{array}{l}\text { Plant } \\
\text { with } \\
\text { fruits }\end{array}$ & Overall & $\begin{array}{l}\text { Picked } \\
\text { leaf } \\
\text { bouquet }\end{array}$ & $\begin{array}{l}\text { Picked } \\
\text { fruit }\end{array}$ & $\begin{array}{l}\text { Cut } \\
\text { fruit }\end{array}$ & Overall & & & \\
\hline \multirow[b]{2}{*}{$\begin{array}{l}\text { How often } \\
\text { infant eats }\end{array}$} & $\begin{array}{l}\text { Natural } \\
\text { food }\end{array}$ & .27 & .099 & .27 & .38 & .10 & .19 & 0.41 & .20 & .034 & .17 \\
\hline & $\begin{array}{l}\text { Processed } \\
\text { food }\end{array}$ & .089 & -.013 & .089 & -.098 & -.12 & -.16 & -.18 & .15 & .17 & -.17 \\
\hline \multirow{2}{*}{$\begin{array}{c}\text { Age of } \\
\text { introduction } \\
\text { to }\end{array}$} & $\begin{array}{l}\text { Whole } \\
\text { fruit and } \\
\text { vegetable }\end{array}$ & .15 & -.013 & .089 & -.16 & .27 & .23 & .11 & .30 & .041 & .054 \\
\hline & $\begin{array}{l}\text { Family } \\
\text { food }\end{array}$ & .19 & .16 & .19 & .39 & .18 & .18 & .36 & .12 & .13 & .27 \\
\hline
\end{tabular}

Table S5. Summary of the correlations between infants' temperament (3 questionnaire items; corrected alpha level 0.017) and the latency for the study objects.

\begin{tabular}{|c|c|c|c|c|c|c|c|c|c|c|}
\hline \multicolumn{11}{|c|}{ Latency } \\
\hline & \multicolumn{3}{|c|}{ Whole plants } & \multicolumn{4}{|c|}{ Processed plant food } & \multirow{2}{*}{$\begin{array}{c}\text { Starchy } \\
\text { food }\end{array}$} & \multirow{2}{*}{$\begin{array}{c}\text { Novel } \\
\text { artifact }\end{array}$} & \multirow{2}{*}{$\begin{array}{c}\text { Naturally } \\
\text { occurring } \\
\text { object }\end{array}$} \\
\hline & $\begin{array}{l}\text { Leafy } \\
\text { plant }\end{array}$ & $\begin{array}{l}\text { Plant } \\
\text { with } \\
\text { fruits }\end{array}$ & Overall & $\begin{array}{l}\text { Picked } \\
\text { leaf } \\
\text { bouquet }\end{array}$ & $\begin{array}{l}\text { Picked } \\
\text { fruit }\end{array}$ & $\begin{array}{l}\text { Cut } \\
\text { fruit }\end{array}$ & Overall & & & \\
\hline Fear & .31 & $\begin{array}{c}.46 \\
p= \\
.0066\end{array}$ & .31 & .25 & .14 & .073 & .12 & .20 & .19 & .20 \\
\hline $\begin{array}{l}\text { Perceptual } \\
\text { sensitivity }\end{array}$ & .18 & .14 & .18 & .077 & .13 & .13 & .17 & .26 & -.072 & .051 \\
\hline Approach & .27 & -.11 & .27 & -.18 & -.045 & .011 & -.097 & .033 & .029 & .018 \\
\hline
\end{tabular}


Table S6. Summary of the correlations between infants' experiences with the outdoor and indoor plants in the last several months (12 questionnaire items; corrected alpha level 0.0042) and proportional social looking.

\begin{tabular}{|c|c|c|c|c|c|c|c|c|c|c|c|}
\hline \multicolumn{12}{|c|}{ Proportional Social Looking } \\
\hline & & Whole & plants & & Processec & plant fo & & & $\begin{array}{l}\text { Starchy } \\
\text { food }\end{array}$ & $\begin{array}{l}\text { Novel } \\
\text { artifact }\end{array}$ & $\begin{array}{l}\text { Naturally } \\
\text { occurring } \\
\text { object }\end{array}$ \\
\hline & & $\begin{array}{l}\text { Leafy } \\
\text { plant }\end{array}$ & $\begin{array}{l}\text { Plant } \\
\text { with } \\
\text { fruits }\end{array}$ & Overall & $\begin{array}{l}\text { Picked } \\
\text { leaf } \\
\text { bouquet }\end{array}$ & $\begin{array}{l}\text { Picked } \\
\text { fruit }\end{array}$ & $\begin{array}{l}\text { Cut } \\
\text { fruit }\end{array}$ & Overall & & & \\
\hline \multirow{7}{*}{$\begin{array}{l}\text { Outdoor } \\
\text { plants }\end{array}$} & $\begin{array}{l}\text { How } \\
\text { often... }\end{array}$ & & & & & & & & & & \\
\hline & $\begin{array}{l}\text { Infant } \\
\text { interacts } \\
\text { with plants }\end{array}$ & .11 & .092 & .11 & .099 & .064 & .0079 & .021 & -.035 & -.0066 & -.029 \\
\hline & $\begin{array}{l}\text { Parents } \\
\text { point } \\
\text { out/name } \\
\text { plants }\end{array}$ & -.092 & -.090 & -.092 & .087 & -.10 & .088 & -.014 & .062 & .069 & -.026 \\
\hline & $\begin{array}{l}\text { Infant sees } \\
\text { parents } \\
\text { caring for } \\
\text { plants }\end{array}$ & .24 & .31 & .24 & .26 & .30 & .14 & .33 & .038 & .25 & .088 \\
\hline & $\begin{array}{l}\text { Infant eats } \\
\text { from plants }\end{array}$ & -.062 & -.023 & -.062 & .23 & .058 & .28 & .21 & .029 & -.040 & .056 \\
\hline & $\begin{array}{l}\text { Infant tries } \\
\text { to touch } \\
\text { plants }\end{array}$ & .023 & .074 & .022 & .13 & -.064 & $\begin{array}{c}- \\
.0012\end{array}$ & -.036 & -.13 & .026 & .0052 \\
\hline & $\begin{array}{l}\text { Parents } \\
\text { stop infant } \\
\text { from } \\
\text { touching } \\
\text { plants }\end{array}$ & -.084 & .10 & -.084 & -.063 & -.43 & .15 & -.030 & -.034 & .12 & -.078 \\
\hline \multirow{3}{*}{$\begin{array}{l}\text { Indoor } \\
\text { plants }\end{array}$} & $\begin{array}{l}\text { Infant } \\
\text { interacts } \\
\text { with plants }\end{array}$ & .034 & .11 & .034 & -.017 & -.094 & $\begin{array}{c}- \\
.0020\end{array}$ & -.10 & -.026 & -.027 & -.015 \\
\hline & $\begin{array}{l}\text { Parents } \\
\text { point } \\
\text { out/name } \\
\text { plants }\end{array}$ & -.051 & .046 & -.021 & -.15 & -.13 & .11 & -.092 & -.056 & -.021 & .043 \\
\hline & $\begin{array}{l}\text { Infant sees } \\
\text { parents }\end{array}$ & .22 & .16 & .22 & .0060 & .028 & -.11 & -.036 & .12 & .058 & -.13 \\
\hline
\end{tabular}


Running head: Avoidance of plant foods in infancy

\begin{tabular}{|c|c|c|c|c|c|c|c|c|c|c|}
\hline $\begin{array}{l}\text { caring for } \\
\text { plants }\end{array}$ & & & & & & & & & & \\
\hline $\begin{array}{l}\text { Infant eats } \\
\text { from plants }\end{array}$ & .10 & .069 & .10 & .0013 & .0039 & -.030 & -.0055 & -.076 & -.060 & -.0085 \\
\hline $\begin{array}{l}\text { Infant tries } \\
\text { to touch } \\
\text { plants }\end{array}$ & .055. & .18 & .055 & .082 & -.019 & .044 & .014 & -.023 & -.060 & -.034 \\
\hline $\begin{array}{l}\text { Parents } \\
\text { stop infant } \\
\text { from } \\
\text { touching } \\
\text { plants }\end{array}$ & .25 & $\begin{array}{c}.43 \\
p= \\
.0032\end{array}$ & .25 & .33 & .16 & .026 & .29 & .25 & $\begin{array}{c}.43 \\
p= \\
.0021\end{array}$ & .24 \\
\hline
\end{tabular}


Table S7. Summary of the correlations between infants' food consumption at home (4 questionnaire items; corrected alpha level 0.0125 ) and proportional social looking.

\begin{tabular}{|c|c|c|c|c|c|c|c|c|c|c|c|}
\hline \multicolumn{12}{|c|}{ Proportional Social Looking } \\
\hline & & \multicolumn{3}{|c|}{ Whole plants } & \multicolumn{4}{|c|}{ Processed plant foods } & \multirow[t]{2}{*}{$\begin{array}{c}\text { Starchy } \\
\text { food }\end{array}$} & \multirow[t]{2}{*}{$\begin{array}{l}\text { Novel } \\
\text { artifact }\end{array}$} & \multirow[t]{2}{*}{$\begin{array}{l}\text { Naturally } \\
\text { occurring } \\
\text { object }\end{array}$} \\
\hline & & $\begin{array}{l}\text { Leafy } \\
\text { plant }\end{array}$ & $\begin{array}{l}\text { Plant } \\
\text { with } \\
\text { fruits }\end{array}$ & Overall & $\begin{array}{l}\text { Picked } \\
\text { leaf } \\
\text { bouquet }\end{array}$ & $\begin{array}{l}\text { Picked } \\
\text { fruit }\end{array}$ & $\begin{array}{l}\text { Cut } \\
\text { fruit }\end{array}$ & Overall & & & \\
\hline \multirow{2}{*}{$\begin{array}{l}\text { How often } \\
\text { infant eats }\end{array}$} & $\begin{array}{l}\text { Natural } \\
\text { food }\end{array}$ & .12 & .11 & .12 & .29 & .083 & .078 & .21 & .072 & -.13 & .26 \\
\hline & $\begin{array}{l}\text { Processed } \\
\text { food }\end{array}$ & -.047 & -.070 & -.047 & -.042 & -.15 & .0011 & -.023 & .14 & -.20 & -.0014 \\
\hline $\begin{array}{l}\text { Age of } \\
\text { introduction }\end{array}$ & $\begin{array}{l}\text { Whole } \\
\text { fruit and } \\
\text { vegetable }\end{array}$ & -.030 & .084 & -.030 & -.03 & .073 & .10 & .08 & .11 & .024 & .18 \\
\hline to & $\begin{array}{l}\text { Family } \\
\text { food }\end{array}$ & .032 & -.035 & .032 & .0010 & .063 & .20 & .17 & -.17 & .089 & .22 \\
\hline
\end{tabular}

Table S8. Summary of the correlations between infants' temperament (3 questionnaire items; corrected alpha level 0.017) and proportional social looking.

\begin{tabular}{|c|c|c|c|c|c|c|c|c|c|c|}
\hline \multicolumn{11}{|c|}{ Proportional Social Looking } \\
\hline & \multicolumn{3}{|c|}{ Whole plants } & \multicolumn{4}{|c|}{ Processed plant foods } & \multirow{2}{*}{$\begin{array}{c}\text { Starchy } \\
\text { food }\end{array}$} & \multirow{2}{*}{$\begin{array}{c}\text { Novel } \\
\text { artifact }\end{array}$} & \multirow{2}{*}{$\begin{array}{c}\text { Naturally } \\
\text { occurring } \\
\text { object }\end{array}$} \\
\hline & $\begin{array}{l}\text { Leafy } \\
\text { plant }\end{array}$ & $\begin{array}{l}\text { Plants } \\
\text { with } \\
\text { fruits }\end{array}$ & Overall & $\begin{array}{l}\text { Picked } \\
\text { leaf } \\
\text { bouquet }\end{array}$ & $\begin{array}{l}\text { Picked } \\
\text { fruit }\end{array}$ & $\begin{array}{l}\text { Cut } \\
\text { fruit }\end{array}$ & Overall & & & \\
\hline Fear & .2 & .14 & .22 & .18 & .18 & -.032 & .078 & $\begin{array}{c}.40 \\
p= \\
.0025\end{array}$ & .059 & .20 \\
\hline $\begin{array}{l}\text { Perceptual } \\
\text { sensitivity }\end{array}$ & .086 & .23 & .086 & .23 & .0095 & -.15 & .21 & .18 & .19 & .20 \\
\hline Approach & .14 & .11 & .14 & .059 & .15 & .12 & .19 & .15 & .076 & .28 \\
\hline
\end{tabular}


Running head: Avoidance of plant foods in infancy

Table S9. Summary of the correlations between infants' experiences with the objects used in the study and Latency and proportional Social Looking toward these particular objects (2 questionnaire items; corrected alpha level 0.025).

\begin{tabular}{|c|c|c|c|}
\hline & & Latency & $\begin{array}{c}\text { Proportional Social } \\
\text { Looking }\end{array}$ \\
\hline \multirow{9}{*}{ How often infant interacts with } & Lemon & -.15 & -.048 \\
\hline & Thai Eggplant & -.23 & -.11 \\
\hline & Papaya & -.00070 & -.19 \\
\hline & Bitter cucumber & & \\
\hline & & .083 & -.10 \\
\hline & Green pasta & .19 & $\begin{array}{c}.31 \\
p=0.017\end{array}$ \\
\hline & Rice cracker & .0060 & -.15 \\
\hline & Natural sponge & -.0014 & -.089 \\
\hline & Shell & -.29 & -.11 \\
\hline \multirow{9}{*}{$\begin{array}{l}\text { How often infant sees parent } \\
\text { interacts with }\end{array}$} & Lemon & -.17 & -.0049 \\
\hline & Thai Eggplant & -.13 & -.12 \\
\hline & Papaya & .18 & -.07 \\
\hline & Bitter cucumber & & \\
\hline & & .083 & -.10 \\
\hline & Green pasta & .088 & .17 \\
\hline & Rice cracker & .038 & -.10 \\
\hline & Natural sponge & -.040 & -.12 \\
\hline & Shell & -.23 & -.12 \\
\hline
\end{tabular}


Running head: Avoidance of plant foods in infancy

Table S10. Summary of how often infants interacted with the particular stimuli used in the study and how often they sees their parent interacting with them (answer were rated on a fivepoint Likert scale: $1=$ never, to $5=$ nearly every day).

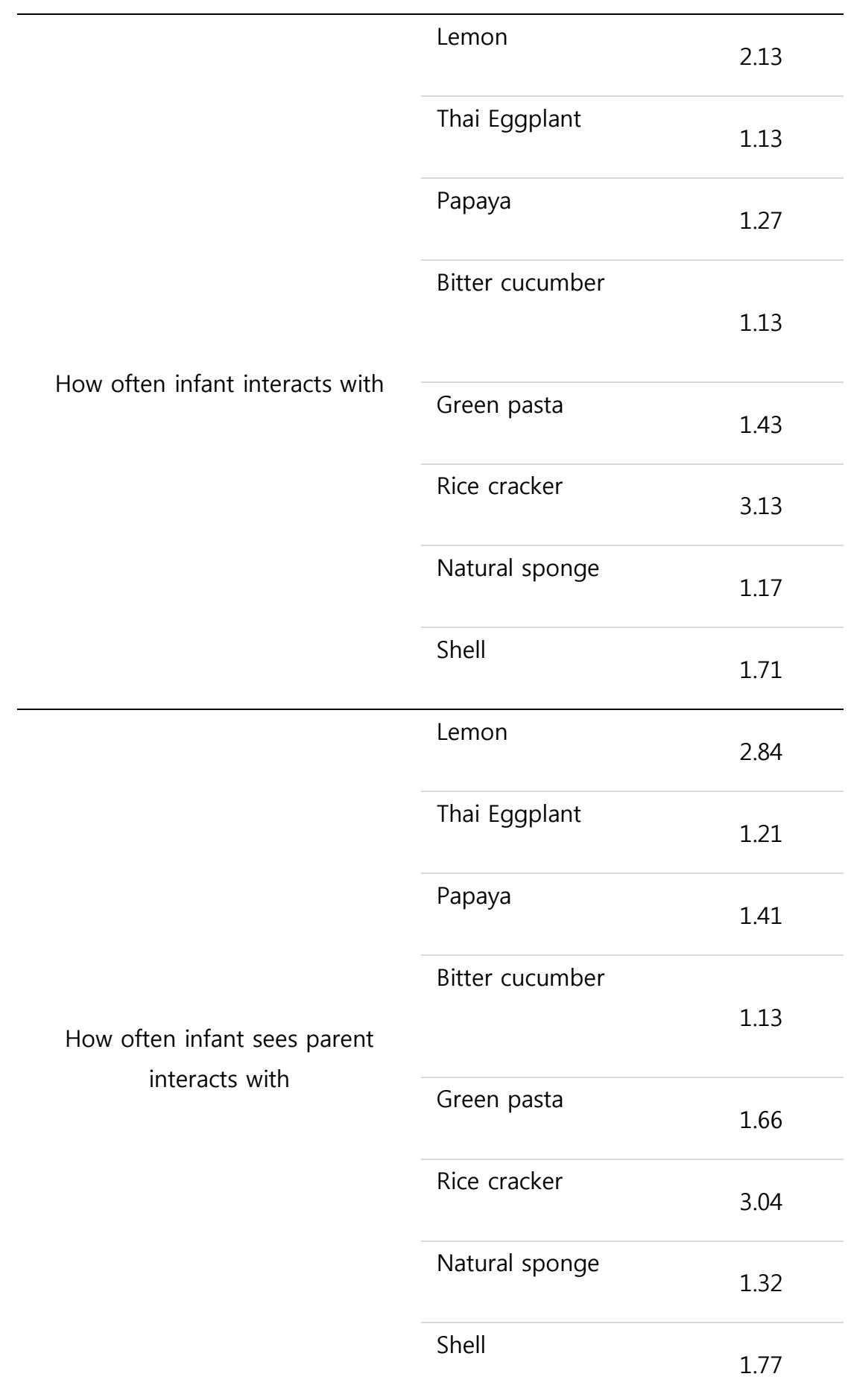


Running head: Avoidance of plant foods in infancy

\subsection{Follow-up assessment of food neophobia}

We conducted correlational analyses to examine whether infants' behavior toward plant foods is related to later food neophobia. Table S11 displays the correlations between infants' latency to touch the study objects and their food rejection tendencies one year later. Table S12 displays the correlations between older infants' latency to touch the study objects and their food rejection tendencies one year later for two other age splits, not presented in the main manuscript. The first older age group corresponds to splitting the sample exactly in half by age, the second corresponds to splitting the sample at 12 months of age following Moding \& Stifter's (2016a) finding that levels of food acceptance at 12 months of age, but not 6 months of age, are associated with later food neophobia. 
Running head: Avoidance of plant foods in infancy

Table S11. Summary of the correlations between infants' latency to touch the study objects and their food rejection tendencies one year later.

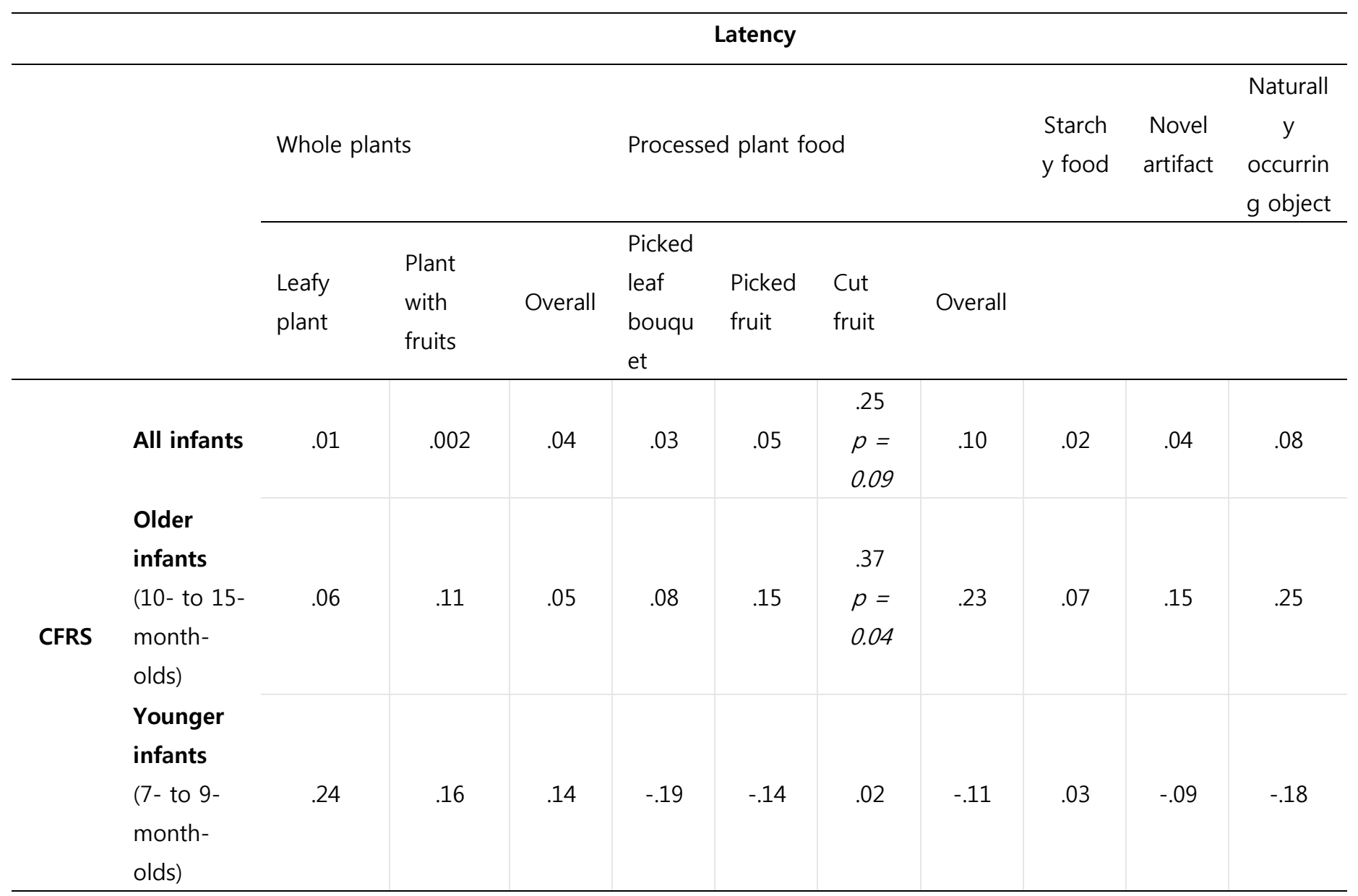


Running head: Avoidance of plant foods in infancy

Table S12. Summary of the correlations between older infants' latency to touch the study objects and their food rejection tendencies one year later for two other age splits.

\begin{tabular}{|c|c|c|c|c|c|c|c|c|c|c|c|}
\hline & \multicolumn{11}{|c|}{ Latency } \\
\hline & & \multicolumn{3}{|c|}{ Whole plants } & \multicolumn{4}{|c|}{ Processed plant food } & \multirow{2}{*}{$\begin{array}{l}\text { Starch } \\
\text { y food }\end{array}$} & \multirow{2}{*}{$\begin{array}{c}\text { Novel } \\
\text { artifact }\end{array}$} & \multirow{2}{*}{$\begin{array}{l}\text { Naturally } \\
\text { occurrin } \\
\text { g object }\end{array}$} \\
\hline & & $\begin{array}{l}\text { Leafy } \\
\text { plant }\end{array}$ & $\begin{array}{l}\text { Plant } \\
\text { with } \\
\text { fruits }\end{array}$ & Overall & $\begin{array}{l}\text { Picked } \\
\text { leaf } \\
\text { bouquet }\end{array}$ & $\begin{array}{l}\text { Picked } \\
\text { fruit }\end{array}$ & $\begin{array}{l}\text { Cut } \\
\text { fruit }\end{array}$ & Overall & & & \\
\hline \multirow{3}{*}{ CFRS } & $\begin{array}{l}\text { Older } \\
\text { infants } \\
\text { (11- to 15- } \\
\text { month- } \\
\text { olds) }\end{array}$ & .02 & .01 & .06 & .08 & .21 & $\begin{array}{l}.42 \\
p= \\
0.03\end{array}$ & .25 & .01 & .17 & .24 \\
\hline & $\begin{array}{l}\text { Older } \\
\text { infants }\end{array}$ & & & & & & .41 & & & & \\
\hline & $\begin{array}{l}\text { (12- to 15- } \\
\text { month- } \\
\text { olds) }\end{array}$ & .15 & .11 & .07 & .08 & .25 & $\begin{array}{l}p= \\
0.06\end{array}$ & .28 & .11 & .19 & .26 \\
\hline
\end{tabular}

Note. Correlations for the younger age groups in both of these age splits were all not significant $(p ’ s>.3)$ 